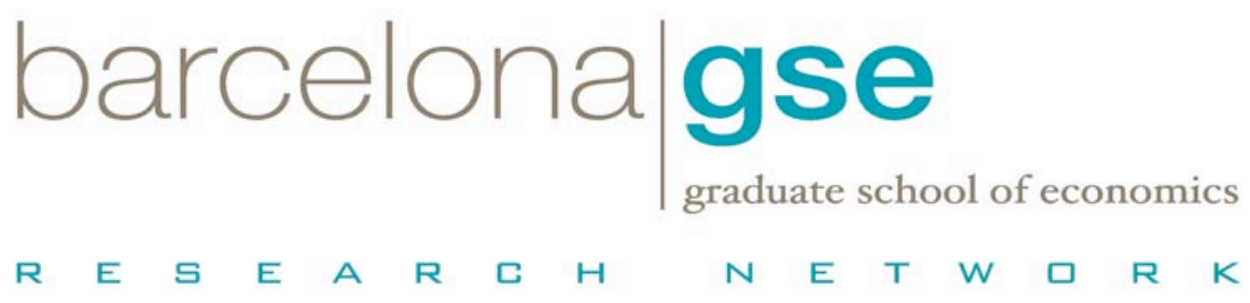

\title{
Caught in the Bulimic Trap? Socioeconomic Status, State Dependence, and Unobserved Heterogeneity
}

\author{
Michelle S. Goeree \\ John C. Ham \\ Daniela lorio \\ May 22, 2009
}

Barcelona Economics Working Paper Series

Working Paper $n^{\circ} 386$ 


\title{
Caught in the Bulimic Trap? Socioeconomic Status, State Dependence, and Unobserved Heterogeneity
}

\author{
Michelle S. Goeree, John C. Ham, and Daniela Iorio ${ }^{1}$
}

May 22, 2009

First version: December, 2008

\begin{abstract}
Eating disorders are an important and growing health concern, and bulimia nervosa (BN) accounts for the largest fraction of eating disorders. Health consequences of BN are substantial and especially serious given the increasingly compulsive nature of the disorder. However, remarkably little is known about the mechanisms underlying the persistent nature of BN and the socioeconomic groups that are most likely to be at risk. Using a unique panel data set on young women and instrumental variable techniques, we document that unobserved heterogeneity plays a role in the persistence of $\mathrm{BN}$, but strikingly up to two thirds is due to true state dependence. Our results, together with support from the medical literature, provide strong evidence that bulimia should be considered an addiction. We also find that African Americans are more likely to exhibit and persist in bulimic behavior than Whites; as are girls from low income families compared to middle and high income families. These results stand in stark contrast to the popular conceptions of who is most likely to experience BN, and we argue that this is due to differences in the diagnosis across racial and income classes. Our findings have important implications for public policy since they i) provide direction to policy makers regarding which adolescent females are most at risk for BN, and ii) suggest that the timing of the policy is crucial: preventive educational programs should be coupled with more intense (rehabilitation) treatment at the early stages of bingeing and purging behaviors. Our results are robust to different model specifications and identifying assumptions.

Keywords: Bulimia Nervosa, Demographics, State Dependence, Instrumental Variables, and Dynamic Panel Data Estimation, Addiction

JEL Codes: I12, I18

\footnotetext{
${ }^{1}$ Michelle S. Goeree (email: goeree@usc.edu) is at the University of Southern California and the University of Zurich; John C. Ham is at the University of Maryland, the Institute for Research on Poverty, and IZA; Daniela Iorio is at Universitat Autonoma de Barcelona. Corresponding author is Goeree (email: goeree@usc.edu). We thank Lynne Casper, James Heckman, Geert Ridder, Seth Sanders, Duncan Thomas and seminar participants at Alicante, Chicago, John Hopkins, IMT-Lucca, RAND, University of Southern California, and the Econometrics Society Meetings (San Francisco) for very helpful comments and discussions, and Heonjae Song for excellent research assistance. We are grateful to the the National Science Foundation, the Claremont McKenna Lowe Institute for Political Economy, the USC College of Letters, Arts and Sciences, the Ministerio de Educación y Ciencia (SEJ2006-00712), Ministerio de Ciencia y Tecnología (SEJ2006-00538), Consolider-Ingenio 2010 (CSD 2006-00016), and Generalitat (Barcelona Economics - xarxa CREA and 2005SGR00836) for financial support. Any opinions, findings, and conclusions or recommendations in this paper are those of the authors and do not necessarily reflect the views of the National Science Foundation. We are responsible for any errors.
} 


\section{Introduction}

Eating disorders are an important and growing health concern in the United States. According to the National Eating Disorders Association (NEDA, 2008), approximately 9 million women in the US struggle with an eating disorder (ED). To put this in perspective, in 2005, approximately 4.5 million people had Alzheimer's disease and about 2.2 million had Schizophrenia. Bulimia nervosa $(\mathrm{BN})$ accounts for the highest number of ED incidents and disproportionately affects women. ${ }^{1} \quad$ Over the last decade 6 to $8.4 \%$ of female adolescents reported purging to lose weight (National Youth Risk Behavior Survey, 2005), and approximately $2.2 \%$ of young women struggled with clinical BN in the unique panel data set we use, the National Heart, Lung, and Blood Institute Growth and Health Study (hereafter the NHLBI Growth and Health survey). In addition, children report suffering from BN at ever younger ages. The average age of onset is between 14 and 25, but the behavior is increasingly seen in children as young as 10 (Cavanaugh and Ray, 1999). Furthermore, only about half of the patients diagnosed with BN fully recover, many experiencing bulimic episodes for decades (Keel et al., 2005).

Bulimia is characterized by recurrent episodes of "binge-eating" followed by compensatory purging. ${ }^{2}$ There are serious health consequences from these binge and purge cycles including electrolyte imbalances that can cause irregular heartbeats, heart failure, inflammation and possible rupture of the esophagus from frequent vomiting, tooth decay, gastric rupture, muscle weakness, anemia, and malnutrition (American Psychiatric Association, 1993). The impact on adolescents and children is even more pronounced due to irreversible effects on physical development and emotional growth. ${ }^{3}$

Given the number of people affected, the seriousness of the effects, and the persistence of the disorder, $\mathrm{BN}$ is a primary health issue. However, public campaigns targeting BN remain scarce, as recently noted by the Senate Committee of Appropriations, who expressed concern about the "growing incidence and health consequences of eating disorders among the population" (Department of Health and Human Services, 2006). ${ }^{4}$ In contrast, there is a major push to

\footnotetext{
${ }^{1}$ Lifetime prevalence of anorexia nervosa is $0.9 \%$ in women and $0.3 \%$ in men (Hudson, et al, 2007). Furthermore, approximately $80 \%$ of BN patients are female (Gidwani, 1997).

${ }^{2}$ Binge-eating is the consumption of an unusually large amount of food (by social comparison) in a two-hour period accompanied by a loss of control over the eating process. Compensatory behavior includes self-induced vomiting, misuse of laxatives, diuretics, or other medications, fasting, or excessive exercise. BN is identified with frequent weight fluctuations.

${ }^{3}$ Irreversible risks include pubertal delay or arrest and impaired acquisition of peak bone mass resulting in growth retardation and increased risk of osteoporosis (Society for Adolescent Medicine, 2003).

4 According to the 2004 School Health Profiles study, only 25 states had a least one school that taught students about EDs. The percent of schools providing ED education in these states ranged from 78 to 99 , where
} 
reduce obesity, and this comes at a cost that receives little or no attention: campaigns fighting obesity could move individuals who are currently bingeing on food to engage in both bingeing and purging behaviors leading to all the negative consequences that arise from BN. ${ }^{5}$ Thus policy aimed at $\mathrm{BN}$ has an important role to play. However, implementation of such a policy is difficult given how little is known about the disorder, as realized by the Senate Committee that emphasized the need for research on the incidence of EDs across demographic groups. For example, popular culture portrays BN as affecting relatively affluent White women who are highly educated, or come from high income family backgrounds but, to our knowledge, there is no multivariate analysis to confirm or deny this assertion. ${ }^{6}$ Thus it is not clear whom should be targeted by public health campaigns. This paper will provide insights on the socioeconomic groups that are more at risk. Also, it is not clear whether the persistence in $\mathrm{BN}$ is due to individual heterogeneity (i.e., some girls have persistent traits that make them more prone to bulimic behavior, but they are not influenced by past experience) or true state dependence (i.e., past BN behavior is an important determinant of current BN behavior) (Heckman, 1981a). Distinguishing between the two explanations has important policy implications. If true state dependence is the most important cause of persistence in $\mathrm{BN}$, and this reflects an addictive component, then it is reasonable to expect that the longer an individual experienced BN the less responsive she will be to policy aimed at combatting the behavior. In this respect the timing of policy is crucial. This is true both in terms of preventive educational programs aimed at instructing girls about the deleterious health effects of $\mathrm{BN}$, as well as treatment interventions. Moreover, we do not know whether the role of state dependence is the same across racial and economic groups; if it is much stronger in some groups then early intervention should pay special attention to these groups.

This is the first paper to i) exploit longitudinal data on individuals' history of bulimic behavior to separate state dependence from individual heterogeneity in BN persistence and ii) to draw a link between true state dependence and the psychiatric and biological literatures on addiction. We also consider static and dynamic linear, Tobit, Ordered Probit and Probit models to investigate the relationship between $\mathrm{BN}$ and socioeconomic status; estimating these models permits us to address the limited dependent nature of our measures of bulimic behavior. We also examine the relationship between BN and personality characteristics (such as body dissatisfaction,

the majority of ED programs were in high schools.

5 In separate work using data from the National Longitudinal Study of Adolescent Health (Goeree, Ham, and Iorio, 2008), we document that women who have been exposed to preventative educational programs on the dangers of being overweight report more severe bulimic behaviors.

6 The epidemiological literature often suffers from one or more of the following problems: i) focuses on univariate correlations, ii) uses select samples, or iii) does not distinguish between correlations and the causal factors behind BN. 
perfectionistic tendencies, and feelings of ineffectiveness and distrust). The medical literature has found univariate correlations between these variables and $\mathrm{BN}$, which may be driven by unobserved genetic factors. We examine whether these personality characteristics continue to be individuality important even when we condition on all of them, demographic variables and a fixed effect to capture unobserved heterogeneity. The empirical findings may justify public health campaigns targeted at improving body satisfaction, or reducing feelings of ineffectiveness and distrust, for reducing BN. ${ }^{7}$ Moreover our results for personality characteristics may offer a relatively direct way to find women at high risk of $\mathrm{BN}$.

We document a number of interesting facts. First, we find that up to two-thirds of BN persistence is due to true state dependence, and the past four years of behavior positively and significantly impact current behavior after controlling for individual heterogeneity. This suggests that policies aimed at instructing a wide range of young women on what constitutes bulimic behavior, and urging them to get help, will be most effective if provided in the early stages. $^{8} \quad$ Further, we make the case for treating $\mathrm{BN}$ as an addiction, rather than only as a disorder. This change would put those exhibiting BN on equal footing (from a treatment reimbursement perspective) with individuals abusing drugs or alcohol. In some states this is a current policy issue, ${ }^{9}$ and in the majority of the states treatment for alcoholism and drug addiction is covered whereas treatment for ED is not covered in as many states (Center for Mental Health Services Report on State Parity Laws, 2008) or is inadequate. ${ }^{10}$

Second, there are important racial and class issues in BN behavior. African Americans are more likely to exhibit and persist in bulimic behavior. The estimates suggest that the impact of past behavior on current behavior is four-fold higher among African Americans. Finally, the incidence of bulimic behavior is decreasing in income, and girls from low income

${ }^{7}$ The power of self-esteem programs for reducing the incidence of ED is demonstrated by the pilot study of O'Dea et al. (2000). They study the effect of an interactive school-based, self-esteem education programs on body image, eating attitudes, and weight loss behaviors in a group of 470 students. After one year students in the treatment group presented significantly greater body satisfaction, while control at risk students significantly decreased their body weight.

${ }^{8}$ Our policy suggestions are consistent with recent findings in the psychiatric literature. For instance, Reas et al. (2000) report that the BN recovery rate is close to $80 \%$ if treatment is given with the first 5 years, but falls to $20 \%$ if treatment is delayed until after 15 years.

${ }^{9}$ Recently the Mental Health Parity Act of 2008 was passed (to be implemented in 2010). The act requires large employer-provided insurance policies that cover mental health or addictions must cover them at the same level as they cover other medical issues. Note that the act does not require policies to cover mental health issues per se. Also, policies that do offer mental health benefits don't have to cover every mental health issue (HR 6983: Wellstone Mental Health Parity and Addiction Equity Act of 2008). State mental health parity laws apply to privately insured plans offered through an employer. These laws vary significantly from state to state.

${ }^{10}$ Daly (2008) found that typical EDs coverageby insurance companies failed to provide adequate reimbursement for the most basic treatment as recommended by the American Psychiatric Association. 
households exhibit the highest persistence. These findings stand in stark contrast to the popular conceptions about $\mathrm{BN}$, and we argue below that this reflects dramatic differences in diagnosis across race and income classes. This in turn has the important implication that much greater outreach for $\mathrm{BN}$ be made to African Americans and to individuals from low income families. We also find that engaging in bulimic behavior is associated with higher body dissatisfaction, feelings of ineffectiveness, and perfectionism. Finally, our results are robust to changes in estimation methods and model specifications and illustrate the importance of using appropriate econometric techniques when studying medical phenomena from survey data.

The outline of the paper is as follows. In section 2 we present a brief review of the ED and addiction literatures. In section 3 we describe the data and present basic statistics on the incidence and persistence of BN. We outline our methodology for studying BN incidence and present our static results in section 4 . In section 5 we present our methodology and results for the dynamic models. In section 6 we interpret our results in the light of medical, biological, and epidemiological literature to relate BN behavior to other behaviors usually considered addictive. We conclude in section 7 .

\section{Literature Review and Background}

The extent of BN in the population, while estimated by several long-term outcome studies as being high, remains unknown. Further, while previous studies have demonstrated differences in education and socioeconomic status for the prevalence of obesity (Lauderdale, 2000; Reeder et al., 1997; Robinson et al., 2001), consistent estimation of the multivariate relationship between factors such as education, social class, and race for the prevalence of $\mathrm{BN}$ is relatively rare. In 2006 the Agency for Healthcare Research and Quality (Department of Health and Human Services, 2006) published a comprehensive review of papers on ED published in epidemiology since 1980. As the report notes, these studies are either descriptive of BN or are focused on the effectiveness of different treatment programs.

To our knowledge the only paper that establishes stylized facts on the connection between demographics, socioeconomic status, and BN is Striegel-Moore et al. (2000). They provide descriptive statistics of BN incidence in the NHLBI Growth and Health Study. They report that $\mathrm{BN}$ is more prevalent among African Americans and that bulimic behavior is higher among girls with low-educated parents. They indicate that this relationship continues to hold in a multivariate setting, but do not report those results. More importantly, they do not consider the dynamic aspects of BN nor issues of persistence or state dependence, which are a primary focus of this paper. Hudson et al. (2007) document the prevalence of various types of ED behaviors among women and men using data from the National Comorbidity Survey Replication. They 
do not examine the relationship of ED with any other socioeconomic factors, nor consider a multivariate setting. Reagan and Hersch (2005) estimate the multivariate effects of socioeconomic factors on bingeing behavior. They investigate the frequency of binge eating (but not purging) using data from the Detroit metropolitan area. They find that there are no race and age effects on bingeing behavior (holding constant gender and obesity status), and that marital status, neighborhood, and income play a role among women. ${ }^{11}$ Unlike Reagan and Hersch (2005) we focus on BN (both binge eating and purging) and we have additional cross-section variables such as parent's education, and somewhat wider geographic variation. Finally, we also explore the association of BN with personality disorders and body dissatisfaction.

In addition, our work differs from all these papers along many important dimensions i) we consider dynamic models and distinguish between persistence due to individual heterogeneity and true state dependence; ii) we allow for racial and income differences in persistence; iii) we examine the case for treating $\mathrm{BN}$ as an addiction and relate our results to those from the medical literature; and iv) we consider nonlinear and fixed effects estimators appropriate for limited dependent variables.

Our work is motivated by evidence that bulimics persist in their behaviors. For example, $35 \%$ of individuals who engaged in past bulimic episodes do so in the future (Keel et al., 2005). Further, only about half of the patients diagnosed with BN fully recover, many experiencing bulimic episodes for decades. The increasingly compulsive nature of ED behaviors suggests that BN may represent an addiction. The ED literature indicates that there is biological support for an addictive interpretation of $\mathrm{BN}$ and some studies have found that genetic factors may play a role in BN incidence (Lilenfeld et al., 1998; Bulik et al., 2003). Specifically, the auto-addiction-opioid theory posits that ED is an addiction to the body's production of opioids (see Vandereycken 2006 for a survey). Starving, bingeing, purging, and exercise increase $\beta$-endorphin levels, resulting in the same chemical effect as that delivered by opiates. Medical research provides further support of this hypothesis. For instance, Bencherif et al. (2005) compare women with BN to healthy women of the same age and weight. They scan their brains using positron emission tomography after injection with a radioactive compound that binds to opioid receptors. The opioid receptor binding in bulimic women was lower than in healthy women in the area of the brain involved in processing taste, as well as the anticipation and reward of eating. This reaction has been found in other studies of addictive disorders, including drug addiction and gambling. Finally, some studies in the biological literature suggest that there may be a genetic component to BN beyond the production of opioids (Bulik et al., 2003).

Patients diagnosed with $\mathrm{BN}$ are likely to suffer from other psychiatric disorders. In a

${ }^{11}$ It is somewhat unusual to condition on obesity, since current obesity will be a function of past bingeing. 
six-year study, Fitcher and Quadflieg (1997) found that 80\% of BN patients suffered from comorbid psychiatric conditions. The most common include depression, anxiety, substance abuse, and personality disorders. ${ }^{12}$ The source of the high comorbidities is not known, but some studies suggest that common familial (Mangweth et al. 2003) or genetic factors (Walters et al. 1992) may be attributed to comorbid mood disorders. ${ }^{13}$ We investigate which personality characteristics are important in a multivariate setting where we also control for demographics, and we allow for the possibility that this relationship is driven by a genetic factor that affects personality characteristics and BN.

The relative importance of state dependence versus individual heterogeneity in explaining the persistence in $\mathrm{BN}$ has been neglected in the literature. In this respect, our work is related to the empirical literature on separating state dependence from unobserved heterogeneity and to the empirical literature on addiction (see, e.g., Becker, Grossman, Murphy, 1994; Baltagi and Griffin, 2001; Labeaga and Jones, 2003; Gilleskie and Strumpf, 2005; for a survey see Chaloupka and Warner, 2000). ${ }^{14}$ There is also a small literature examining whether addiction to food may be a contributing factor to the rise in obesity. For example, Cawley (2001) is concerned with addictive elements of caloric intake; Richards et al. (2007) of food nutrients; and Rashad (2006) of caloric intake, smoking, and exercise. These papers find evidence of a forward looking addiction to calories (Cawley, 2001) and to carbohydrates (Richards et al., 2007). The large and growing literature on obesity is related to our work in the broad sense that it pertains to food consumption, but is otherwise unrelated given that women suffering from $\mathrm{BN}$ are characterized by average body weight (Department of Health and Human Services, 2006).

\section{Data}

We use the NHLBI Growth and Health survey, which includes girls from schools in Richmond, California and in Cincinnati, Ohio, as well as from families enrolled in a health maintenance organization in the Washington, DC area. ${ }^{15}$ The survey was conducted annually for ten years,

\footnotetext{
12 See the scientific papers cited in Department of Health and Human Services (2006).

${ }^{13}$ See Borghans et al. (2008) for a discussion of the relevance of personality traits in predicting social and economic outcomes.

14 Becker, Grossman and Murphy (1994) used the framework of Becker and Murphy (1988) to examine whether addiction to cigarettes is rational, i.e. whether individuals consider that, due to the addictive nature of the behavior, their actions today will affect their future behavior and utility. For addiction to be rational, both leads and lags of the behavior should (positively) affect current behavior after controlling for unobserved heterogeneity. We have too short a panel to consider a model of rational addiction.

${ }^{15}$ Unfortunately, because of confidentiality concerns, the data do not indicate in which of these three sites an individual lives. Selection of potential schools was based on census tract data that showed approximately equal
} 
and began in 1988 when the girls were aged 9-10. ${ }^{16}$ It contains substantial demographic and socioeconomic information such as age, race, parental education, and initial family income (in categories). The data also contain a number of time-varying psychological or personality indices (reflecting the potential for personality disorders).

A notable aspect of the data is that all individuals were asked a number of questions about their bingeing and purging behavior. For each respondent the data contain an Eating Disorders Inventory index developed by a panel of medical experts, which was designed to assess the psychological characteristics relevant to bulimia (Garner et al., 1983). Thus a major advantage of these data is that all sample participants are evaluated regarding BN behaviors, and a BN eating disorder index is developed for each participant independent of any diagnoses or treatment they have received. This stands in contrast to many data sets, where often a measure of ED or BN behavior is only available if the respondent had been diagnosed with, or was being treated for, an ED. However, if individuals from certain income or racial groups are more likely to seek treatment for an ED, results based on data from diagnosed individuals can present a very misleading picture of the incidence of EDs. Indeed we present evidence below that suggests this is a real problem, not just a potential one.

The NHLBI Growth and Health survey was constructed to have equal numbers of African Americans and Whites, and to have approximately equal representation across different income groups for African Americans and Whites (Kimm et al., 2002). While it is not a nationally representative sample, the stratification by race and income are ideal for examining the role that these demographics play in the incidence and persistence of BN. For example, we would need a much larger (and nationally representative) sample to examine differences between Whites and African Americans. Whether our coefficient estimates are useful for examining national trends depends on the degree of parameter heterogeneity. For example, if equations describing the incidence and persistence of $\mathrm{BN}$ have constant coefficients, our results will be nationally representative for Blacks and Whites; if the coefficients differ, say across urban and rural locations, our results can be thought of as estimating the urban coefficients. Since we treat race and family income as exogenous, there is no bias from stratifying on these variables. ${ }^{17}$

fractions of African American and White children, and the least disparity in income and education between the respondents of the two ethnic groups. The majority of the cohort, selected via the Health Maintenance Organization (HMO), was randomly drawn from a membership list of potentially eligible families with nine (or ten) year-old girls. A small percentage was recruited from a Girl Scout troop located in the same geographical area as the HMO population.

16 The attrition rate after ten years was $11 \%$.

17 If coefficients differ across the nation in other ways, one could obtain nationally representative estimates by reweighting. Given our emphasis on the role of race and income, we have not used reweighted data. 
To the best of our knowledge the NHLBI Growth and Health survey has not been used previously in economics, so we now describe the data and variable construction in some detail. The data consist of ten waves of 2379 girls. Starting in 1990, when the girls were aged 11-12, the survey contains questions on BN behavior that were asked approximately every other year (in waves $3,5,7,9$, and 10). The questions were formulated to be consistent with the clinical definition of $\mathrm{BN}$ and were adjusted to be easy to understand for young respondents. ${ }^{18}$

The survey reports an Eating Disorders Inventory Bulimia subscale for each respondent (hereafter the ED-BN index), which measures degrees of her behavior associated with BN. The ED-BN index is constructed based on the subjects responses ( "always" =1, "usually" =2, "often" $=3$, "sometimes" $=4$, "rarely" $=5$, and "never" =6) to seven items: 1) I eat when I am upset; 2) I stuff myself with food; 3) I have gone on eating binges where I felt that I could not stop; 4) I think about bingeing (overeating); 5) I eat moderately in front of others and stuff myself when they are gone; 6) I have the thought of trying to vomit in order to lose weight, and 7) I eat or drink in secrecy. A response of 4-6 on a given question contributes zero points to the ED-BN index; a response of 3 contributes 1 point; a response of 2 contributes 2 points; and a response of 1 contributes 3 points. For instance, if a respondent answers "sometimes" to all questions, her ED-BN index will be zero. The ED-BN index is the sum of the contributing points and ranges from 0 to 21 in our data. Note that the answers to the individual questions are not available in the data.

A higher ED-BN score is indicative of more BN related problems that are characterized by uncontrollable eating episodes that may be followed by the desire to purge. According to the team of medical experts that developed the index (Garner et al., 1983), a score higher than 10 indicates that the girl is very likely to have a clinical case of BN. The quantitative interpretation in terms of who is perceived to be suffering from clinical BN is motivated by results from surveys among women diagnosed with BN (by the Diagnostic and Statistical Manual of Mental Disorders (DSM-IV) criteria): the average ED-BN index among this subsample was 10.8. ${ }^{19}$ For this reason, we will refer to a value of the ED-BN index of greater than 10 as clinical bulimia for the remainder of the paper. The ED-BN index is widely used in epidemiological and ED studies (Rush et al., 2008).

The NHLBI Growth and Health survey also contains questions used to construct four other indices based on psychological criteria. These indices were developed by a panel of medical

18 Clinical criteria for BN, according to the Diagnostic and Statistical Manual of Mental Disorders fourth edition (American Psychiatric Assocation, 2000a), requires the cycle of binge-eating and compensatory behaviors occur at least two times a week for three months or more and that the individual feel a lack of control during the eating episodes. Due to data restrictions, we cannot examine the prevalence of anorexia nervosa.

19 See Garner et al. (1983) for more details of the development and validation of the ED-BN index. 
experts (see Garner et al., 1983 for a discussion of the association of these personality characteristics with EDs). The four additional indices measure a respondent's potential for personality disturbances, and below we refer to these indices collectively as the "personality indices." The first index is a measure of each girl's dissatisfaction with her body. This index is reported every year and is a sum of respondents answers to nine items intended to assess satisfaction with size and shape of specific parts of the body. Hereafter we refer to it as the body dissatisfaction index. We also use three additional indices that are based on psychological criteria, measuring tendencies toward: perfectionism (hereafter the perfectionism index), feelings of ineffectiveness (hereafter the ineffectiveness index), and interpersonal distrust (hereafter the distrust index). These indices are available in waves 3, 5, 9, and 10 and thus overlap with the ED-BN index availability, with the exception that the ED-BN index is also available in wave 7 . For ease of exposition, we provide details on the questions used to form the personality indices in Appendix A. In all cases a higher score indicates a higher level of the personality characteristic.

We report variable means, standard deviations, and the standard errors for the mean values of the NHLBI Growth and Health sample in Table 1. For all demographic variables except age we have one observation per person, while for the other variables we have multiple observations per person; we adjust the standard errors of the mean to take this into account. Approximately $2.2 \%$ of the girls have a case of clinical $\mathrm{BN}$, which is close to the national average reported from other sources, ${ }^{20}$ while the mean of the ED-BN index is 1.2. The average age of the girls over the sample is approximately 14 years, and, as expected given the sample design, it is approximately equally distributed across race, income, and parent's education level. ${ }^{21}$

Table 2 illustrates the univariate relationship between the demographic variables, the ED$\mathrm{BN}$ index, and $\mathrm{BN}$ incidence. In the upper panel, for a given demographic group, we present the mean, standard deviation, and the standard error of the mean for the ED-BN index in columns (1)-(3), respectively. Columns (4)-(6) present the same statistics for the incidence of clinical BN. Again, in each case we cluster the standard errors (by individual) for the means. Note first that as the girls age, both the ED-BN index and BN incidence fall. Interestingly, African American girls have a statistically significant higher ED-BN index and incidence of clinical BN than White girls. This finding is not a result of an incorrect interpretation of what the ED-BN

\footnotetext{
20 See for instance, Hudson et al. (2007) and National Eating Disorders Association (2008).

${ }^{21}$ In almost $20 \%$ of the individual-wave observations, the girls report being depressed (they were asked about their problems with depression in waves 7 and 9). Those who are depressed have statistically significant higher ED-BN indices and incidence of clinical BN. The high comoribity of depression and ED behaviors is well-documented (see Department of Health and Human Services, 2006). We do not include depression as an explanatory variable in our analysis due to problems associated with reverse causality from BN to depression, for which we do not have an adequate instrument. The issue of reverse causality from BN to depression does not seem to have been recognized in the previous literature.
} 
index measures, i.e. the possibility that it might capture obesity (binge eating) instead of BN behaviors since, if this were the case, we would expect that higher ED-BN scores would be associated with a higher body mass index (BMI). However, BMI is decreasing in ED-BN for African Americans. Moreover, for African Americans average BMI for girls with an ED-BN index above 5 is lower than average BMI for girls with an index of 5 or lower (22.48 versus 24.72, respectively). Similarly for Whites, average BMI associated with an ED-BN index above 5 is lower than that associated with an index of 5 or lower (20.55 versus 22.14 , respectively). These statistics strongly suggest that the ED-BN index is not an obesity index. ${ }^{22}$ Both the ED-BN index and the incidence of clinical BN decrease as parental education and family income increase, and again these differences are statistically significant at standard confidence levels. These results suggest that BN is more problematic among African American girls, girls from low income families, and girls from families with low parental education. Thus they stand in sharp contrast to popular conceptions about the incidence of BN. One possibility is that these univariate results will disappear once we condition on the personality indices, and that some will disappear once we condition on the other demographic variables. However, the results in the next section indicate that the differences for race and family income persist in a multivariate setting even after conditioning on the personality characteristics indices. In the lower panel of Table 2 we present the univariate correlations between each of the personality indices with both the ED-BN index and the incidence of clinical BN. In all cases these correlations are positive and statistically significant at the $1 \%$ level.

Finally, we present summary statistics on the persistence in the ED-BN index and the incidence of clinical BN to motivate our dynamic estimation. To look at persistence in the index we consider four categories of the ED-BN index: equal to 0 , in the range [1 - 5], in the range $[6-10]$, and greater than 10 . Table 3 provides the transition rates across two year intervals for these categories. Note first that the higher is the ED-BN category the lower is the probability of having an index value of 0 two years later (i.e., at time $t+1$ ). Second, the higher the category for the index in $t$, the more likely the ED-BN index lies between 6 and 10 in $t+1$. Finally the higher the ED index in $t$, the more likely is the girl to be in the greater than 10 category at $t+1$, i.e., the more likely she is to have clinical bulimia. For instance, the conditional probability of having clinical $\mathrm{BN}$ in $t+1$ given that a girl has it in $t$ is $20 \%$, while the same probability for someone with a ED-BN index in the range $[1-5]$ in $t$ is $2 \%$ and it is less than $0.05 \%$ for someone with an index equal to zero in $t .^{23}$ If we simply look at the correlation between the index in $t$ and the index in $t+1$, we estimate it to be 0.48 , and, not

\footnotetext{
${ }^{22}$ This result is consistent with the DSM-IV, which states that bulimics are characterized by average BMI.

${ }^{23}$ The same general pattern comes through when we consider a more narrow breakdown of the ED-BN index.
} 
surprisingly, this estimate is very statistically significant. We draw two conclusions from these results. First, there is substantial persistence in the ED-BN index and the incidence of clinical BN, motivating our use of dynamic models. Second, the first set of transition rates indicates that knowing the value of the ED-BN index is important for predicting the incidence of clinical $\mathrm{BN}$ in $t+1$, so simply aggregating the ED-BN index into an incidence of clinical BN would discard valuable information. Indeed our results presented below show that coefficients are of the same sign when we analyze the ED-BN index and the incidence of clinical BN, but the former are much more precisely estimated.

\section{Static Models of BN}

In this section we examine the predictive role of socioeconomic status (SES) and personality indices in the incidence and intensity of bulimic behaviors. These results are policy relevant as they provide insight into which girls are at the greatest risk for $\mathrm{BN}$ and thus guide the direction of future outreach.

\subsection{Empirical Models}

We consider results from four model specifications: i) a linear regression structure that treats a zero value of the ED-BN index as lying on the regression line; ii) a Tobit structure for the ED-BN index; iii) a linear probability model (LPM) for the incidence of clinical BN (i.e., a value for the ED-BN index greater than 10) and iv) a Probit model for the incidence of clinical $\mathrm{BN}$. It is important to note that the ED-BN index function is based solely on behavior and is not in any way based on diagnosis. This is an advantage if, as we argue below, certain groups are much more likely to seek medical attention for bulimic behavior. ${ }^{24}$

We first use these models to examine the relationship between the ED-BN index and the SES. We then augment these models by including personality indices as explanatory variables since the medical literature suggests that these indices will be very highly correlated with the ED-BN index. To begin we estimate a linear regression (projection) of the observed value of the ED-BN index on the independent variables:

$$
y_{i t}=\beta_{0}+\beta_{1} X_{i t}+a_{t}+\delta_{i}+v_{i t}
$$

where $X_{i t}$ is a vector of explanatory variables (demographics and the personality indices described above) for individual $i$ at time $t, a_{t}$ is a time dummy (which we sometimes drop), $\delta_{i}$

\footnotetext{
${ }^{24}$ We do not know whether the respondent has been diagnosed with, or is being treated for, clinical BN.
} 
is an individual-specific effect and $v_{i t}$ is a contemporaneous shock. To begin with we treat $\delta_{i}$ as uncorrelated with the explanatory variables, and cluster the standard errors by individual to control for correlation across time due to individual components, as well as the induced heteroskedasticity in the linear models.

For the Tobit, we assume that the latent variable underlying the ED-BN index is

$$
y_{i t}^{*}=\varphi_{0}+\varphi_{1} X_{i t}+b_{t}+\mu_{i}+e_{i t},
$$

where the change in notation is obvious. The observed value, $y_{i t}$, of the ED-BN index is

$$
y_{i t}=\left\{\begin{array}{c}
0 \text { if } y_{i t}^{*} \leq 0 \\
y_{i t}^{*} \text { otherwise. }
\end{array}\right.
$$

We begin by assuming that $\mu_{i}$ is an independently and identically distributed (across individuals) $N\left(0, \sigma_{\mu}^{2}\right)$ individual-specific random effect and that $e_{i t}$ is i.i.d. $N\left(0, \sigma_{e}^{2}\right)$ (over time and individuals). We then estimate the model by forming a quasi-likelihood of the period by period observations and cluster the standard errors by individual. ${ }^{25}$ We compare the regression coefficients to the Tobit partial effects, and find (as one would expect) that they are very similar for the static models.

We discussed in section 3 the possibility that the personality characteristics may be driven by time constant genetic factors. If these time constant genetic factors also affect $\mathrm{BN}$, the individual specific component of the error term in the ED-BN equations will be correlated with the personality characteristics, and the coefficients on these independent variables will not be consistently estimated. To allow for correlated individual effects in the regression, we first difference and only the time-changing independent variables remain. Also, as in any fixed effect model, to estimate these equations consistently we need to assume that the personality indices are strictly exogenous, conditional on the fixed effect. ${ }^{26}$ This rules out feedback from current values of the error term to future values of the explanatory variables. The strict exogeneity assumption may be more reasonable for the perfectionism, ineffectiveness and distrust indices than for the body dissatisfaction index, since a shock to BN behavior today may affect one's body dissatisfaction tomorrow. Thus we also estimate models where we only include these personality indices and exclude the body dissatisfaction index.

\footnotetext{
${ }^{25}$ We cannot allow for heteroskedasticity when clustering, since Tobit estimates are inconsistent unless errors are homoskedastic. We also estimated random effects Tobit models, which offer efficiency gains at the cost of assuming that the error structure is covariance stationary and that the correlation coefficient is the same across individuals. The results were very similar to the ones reported in the paper.
}

26 See Wooldridge (2002), p. 253, equation (10.14). 
In the Tobit models, we use the Chamberlain (1984)/Wooldridge (2005) (hereafter C/W) approach to allow for correlated random effects. ${ }^{27}$ Specifically, for the Tobit model of equation (2) we assume that $\mu_{i}=\pi_{1} \bar{X}_{i}+u_{i}$ where $\bar{X}_{i}$ is the vector of means of the explanatory variables across time, $u_{i} \sim$ iid $N\left(0, \sigma_{u}^{2}\right)$. This yields

$$
y_{i t}^{*}=\varphi_{0}+\varphi_{1} X_{i t}+b_{t}+\pi_{1} \bar{X}_{i}+u_{i}+e_{i t} .
$$

We again maximize the quasi-likelihood and cluster the observations across individuals when calculating standard errors.

We also consider Probit and LPM specifications as robustness checks on the regression and Tobit results. The signs should be similar to the models discussed above, but we expect the parameters to be less precisely estimated since these models use much less information. To allow for fixed effects we difference the LPM and use the C/W approach with the Probit model. ${ }^{28}$

\subsection{Static Results}

In Table 4 we present the estimates from a number of estimators where we include socioeconomic variables; in the lower panel we also include year dummies. For the Tobit and Probit models we report partial effects. The vector $X_{i t}$ contains the respondent's age, a dummy variable for White, two dummy variables for parent's education (some college and four year college degree or more) and two dummy variables for initial family income (between $\$ 20,000$ and $\$ 40,000$ and over $\$ 40,000$ in $\$ 1988$ ). Thus the base case is an African American girl whose parents' have a high school education or less, with a family income under $\$ 20,000$. The coefficients for the linear model and the partial effects for the Tobit model are very similar in terms of size and significance, so we discuss only the former. They show that the effect of being White, holding the other variables constant, is significantly negative. In terms of magnitude, being White lowers the ED-BN index by 0.24 , which is about a $20 \%$ reduction relative to the mean value (of 1.2), holding all else equal (in what follows we do not repeat the latter qualification). Further, the ED-BN index is significantly decreasing in age; each additional year of aging decreases the

\footnotetext{
${ }^{27}$ Chamberlain (1984) suggested controlling for the fixed effect by making it a linear function of all the values of the explanatory variables, while Wooldridge (2005) suggested making it the means of the independent variables. We follow Wooldridge since it makes our estimates more comparable to our dynamic fixed effect estimates.

${ }^{28}$ We also consider an Ordered Probit model based on ED-BN index categories equal to $0 ; 1-5 ; 6-10$ and greater than 10., which is more flexible than the Tobit (due to estimated limit points). However, the coefficients are not directly comparable as we must normalize the variance, but the coefficients should be of the same sign and approximate significance. This is indeed what we find; the results are in the online Appendix (Goeree, Ham, and Iorio, 2009). We use $\mathrm{C} / \mathrm{W}$ when we consider correlated random effects.
} 
ED-BN index by about $10 \%$ of its mean value. ${ }^{29} \quad$ Perhaps equally surprising as the results for African Americans, the index is also significantly decreasing in family income; being middle income lowers the index by about 0.38 (a $32 \%$ reduction relative to the mean) as compared to the lowest income group, while being in the highest income group lowers the index by about 0.49 (more than a $40 \%$ reduction relative to the mean) as compared to the lowest family income. Having the highest parental education significantly lowers the index by 0.31 (a $26 \%$ reduction of the mean value) as compared to those with the lowest parental education, while having parents with some college education lowers the ED-BN index by a (significant) 0.20 . When we include year dummies (the lower panel of Table 4), only the coefficients for age are affected, and these coefficients are now estimated imprecisely. This latter result is not surprising given we do not have much variation in age at the start of the sample, so the girls in our sample tend to act like a single cohort. Finally, the Probit partial effects and LPM coefficients in columns (3) and (4) respectively, have similar signs as the linear regression and Tobit coefficients, but as expected, are much less likely to be statistically significant.

The regression and Tobit results for race, income and education are substantial, statistically significant, and present a challenge to the widespread perception that bulimia primarily affects privileged, White teenagers. Further, as we show below, these findings remain even after we condition on personality characteristics. An interesting question is why does this divergence between our results and popular conceptions occur? We believe the explanation is straightforward: popular opinion appears to be based on who has been diagnosed with an eating disorder, not (the potentially larger and different group) of those who exhibit BN behavior. The difference would appear to arise because girls who are African American and/or come from low income families are much less likely to be diagnosed with an ED conditional on having an ED. This is supported by results from a companion paper (Goeree, Ham and Iorio, 2008) in which we use data from the National Longitudinal Study of Adolescent Health (ADD Health) and consider two groups of women: those who are diagnosed with an ED and those who engage in bingeing and purging behavior. We find that diagnosis is more likely among high-income Whites (consistent with popular opinion), but the incidence of bingeing and purging behavior is consistent with the results we report here. ${ }^{30}$ These results illustrate the importance of having objective information on behavior rather than only data on diagnoses, and have the

${ }^{29}$ We included quadratic effects in age. The estimates imply that going from age 12 to 14 (14 to 16$)$ decreases the ED-BN index by $0.20(0.15)$.

${ }^{30}$ In Goeree, Ham, and Iorio (2008) we use ADD Health to address different issues. The ADD Health data are not a long enough panel to allow us to estimate dynamic models needed to investigate the persistent nature of BN. 
policy implication that outreach should be made to low income and African American girls. ${ }^{31}$

We next look at the effect of the personality indices on the ED-BN index, holding constant the demographic variables. As we noted in the related literature section, it is well known that patients diagnosed with BN are also likely to suffer from other psychiatric disorders such as depression, anxiety, or substance abuse. We do not include these variables for two reasons: data limitations (we only observe depression, and then only in 2 waves), and it is not clear which way the causality would go, i.e., abusing food may lead to depression and anxiety. As noted above, this reverse causality may also occur with body dissatisfaction, and thus we estimate most of our models with and without body dissatisfaction.

Table 5 contains the results for the linear and Tobit models where personality indices are included as explanatory variables and the year dummies are dropped. We begin by estimating the linear model in levels and column (1) presents results with the distrust, ineffectiveness and perfectionism indices (but not the body dissatisfaction index) used as explanatory variables, while in column (2) we also include the body dissatisfaction index. Note first that race, age and family income, but not parental education, are still statistically significant when we condition on personality indices (independent of which ones we condition on), although the size of the income differentials, but not the race differential, is substantially reduced. Second, the ineffectiveness, perfectionism and body dissatisfaction indices, but not the distrust index, significantly affect the ED-BN index in the direction expected. Third, the effects of increases in the personality characteristics are substantial. Since the personality indices and the ED-BN are (almost) continuous variables, it is perhaps most illuminating to consider elasticities measured at mean values from Table 1. Using the estimates in column (2), we find large elasticities of the EDBN index with respect to the ineffectiveness, perfectionism, and body dissatisfaction indices are $0.56,0.68$, and 0.25 , respectively. Alternatively, a (separate) five point increase in the ineffectiveness index and perfectionism index each increase the ED-BN index by about 1.3 and 0.7 respectively, while a (separate) five point increase in the body dissatisfaction index increases the ED-BN index by about 0.2. Note that each of these effects is substantial when compared to the mean ED-BN index of 1.2.

Column (3) reports the first difference estimates of the linear model, which will eliminate an unobserved genetic fixed effect that could potentially drive both the personality indices and the ED-BN index. ${ }^{32}$ These results are quite similar to those from the level estimates in terms

31 Girls from White and/or high income families may be receiving treatment that mitigates BN behavior. Then, if this is true, in the absence of any treatment, African Americans and Whites, or low-and high-income girls, may not differ in their propensity for BN. Even if this is the case, there still is a large untreated group (e.g., African Americans and low-income families) currently overlooked at whom outreach should be aimed.

32 The demographic variables are measured at the start of the survey and thus drop out of the first difference 
of the magnitude and significance of the coefficients on the personality indices. ${ }^{33}$ In this case, the elasticities of the ED-BN index with respect to ineffectiveness, perfectionism, and body dissatisfaction indices are $0.42,0.66$, and 0.30 respectively. Note that these are very similar to what we found when we do not allow for a fixed unobserved effect that could be causing a spurious correlation between the personality indices and ED-BN index. ${ }^{34}$ As a robustness check, column (4) presents the results with $\mathrm{C} / \mathrm{W}$ correlated random effects, where the signs and significance of these estimates are reassuringly similar to the first difference estimates. This comparison is helpful as it suggests that parameter estimates in the nonlinear models are not biased by the more restrictive assumptions necessary to use the $\mathrm{C} / \mathrm{W}$ approach, since we cannot use first differences in the nonlinear models.

Columns (6) to (8) contain the partial effects for the Tobit model when we include the personality characteristics as explanatory variables. The results are quite close to (if a bit smaller than) those from the linear model, except that the distrust variable now has a (expected) significant positive coefficient in the levels equation and an insignificant coefficient in the correlated random effects specification in column (7). Thus each of the personality indices (except the one for distrust) continue to be strongly related to ED-BN behavior when we condition on other personality indices and demographic variables, and when we take out a fixed effect that may represent common genetic factors. These results shed light on the potential effectiveness of preventive programs that improve self-esteem, body satisfaction, or other related personality characteristics in targeting girls suffering from BN. They may also help to detect girls engaging in $\mathrm{BN}$ if non-anonymous questionnaires about personality characteristics are more likely to illicit truthful responses than those directly asking about bulimic behavior. ${ }^{35}$

In columns (5) and (8) we include race-income interactions after controlling for personality indices for linear and Tobit models, respectively. The base case is African Americans from the lowest income households. The coefficients indicate the low and middle income African Americans have the strongest tendency towards bulimic behavior. More specifically, among

model.

33 The only difference being that the coefficient on distrust is statistically significant and has an (unexpected) negative sign. Note that the distrust coefficient is significant and has the expected sign in the Tobit regression.

${ }^{34}$ We cannot use the standard formula to do a Hausman test for the null hypothesis that there is no correlation between the personality indices and the fixed effect since the estimates in column (2) are not fully efficient due to heteroskedasticity and intra-individual correlation. Instead, we could use a bootstrap approach to obtain a standard error for the difference in the coeffients between columns (2) and (3), but given how close the estimates for the personality indices are in (2) and (3), this step did not seem necessary.

${ }^{35}$ For instance, the personality indices are constructed from less intrusive statements about the respondent's feelings and beliefs, whereas the ED-BN questions are about actions that might be perceived as abnormal by the respondent. 
African Americans, girls from high income households have an ED-BN index that is 34\% (at the mean ED-BN) lower than girls from low income families. However, among Whites, low income girls have substantially higher propensity toward BN than both middle and high income girls. Further, middle (high) income Whites present an ED-BN index that is $48 \%$ (36\%) lower than low income African Americans. Finally, among the lowest income households ethnicity still plays a significant role: the ED-BN index for Whites drops by about $25 \%$ (of the overall mean). Thus there appear to be interesting race-income interactions in BN.

\section{BN Persistence: State Dependence or Individual Het- erogeneity?}

Our goal in this section is to study the degree of persistence in bulimic behavior, and to decompose this persistence into that due to state dependence (i.e., BN behavior in the past has a causal effect on BN behavior this period) and that due to observed and unobserved heterogeneity (i.e., some girls have persistent traits that make them more prone to bulimic behavior). We then discuss racial and income differences in persistence.

\subsection{Empirical Dynamic Models}

We begin with the most basic model

$$
y_{i t}=\beta_{0}+\beta_{1} y_{i t-1}+\widetilde{\delta}_{i}+v_{i t},
$$

where $y_{i t-1}$ is the lag of the observed value of the ED-BN index and we drop the year dummies for ease of exposition. ${ }^{36}$ The least squares estimate of $\beta_{1}$ will reflect both observed and unobserved heterogeneity as well as true state dependence. To account for observed heterogeneity we include current explanatory variables $X_{i t}$ to obtain

$$
y_{i t}=\beta_{0}+\beta_{1} y_{i t-1}+\beta_{2} X_{i t}+\delta_{i}+v_{i t}
$$

The parameter $\beta_{1}$ will now reflect both unobserved heterogeneity and true state dependence, and we are particularly interested in the role of the latter in the persistence in (5). To address this issue we take two approaches. First, we assume that $\delta_{i}$ and $v_{i t}$ are uncorrelated with $X_{i t}$ and its lags and use the time changing portion of $X_{i t-1}$ as excluded instrumental variables

\footnotetext{
${ }^{36}$ If we add time dummies in any dynamic model the only real change is that age becomes very insignificant.
} 
$(\mathrm{IV})^{37}$ when estimating (5) to obtain an estimate of $\beta_{1}$ that reflects only state dependence. ${ }^{38}$

Second, we relax the assumption that $\delta_{i}$ and $v_{i t}$ are uncorrelated with $X_{i t}$ and its lags by following Anderson and Hsiao (1981) and Arellano and Bond (1991; hereafter AB). Specifically, we first difference (5) to obtain

$$
\Delta y_{i t}=\beta_{0}+\beta_{1} \Delta y_{i t-1}+\beta_{2} \Delta X_{i t}+\Delta v_{i t},
$$

and estimate the parameters by 2SLS using $y_{i t-2}$ and lagged $\Delta X_{i}$ as IV under the assumption that $v_{i t}$ is uncorrelated over time. These are valid IV under the assumption that $v_{i t}$ is not correlated over time; below we test this assumption and find that we cannot reject it. Taken together, the results of the two approaches are informative of whether our estimates are sensitive to our identifying assumptions.

For the Tobit model, we start by considering the simplest latent variable equation

$$
y_{i t}^{*}=\varphi_{0}+\varphi_{1} y_{i t-1}+\widetilde{\mu}_{i}+e_{i t}
$$

where $\widetilde{\mu}_{i}$ are (unobserved) individual-specific random effects and $e_{i t}$ is an uncorrelated (over time) error term, both of which are normally distributed. The estimate of $\varphi_{1}$ will capture observed and unobserved heterogeneity and true state dependence. To account for observed heterogeneity we add explanatory variables $X_{i t}$ to obtain

$$
y_{i t}^{*}=\varphi_{0}+\varphi_{1} y_{i t-1}+\varphi_{2} X_{i t}+\mu_{i}+e_{i t},
$$

where now the estimate of $\varphi_{1}$ will reflect unobserved heterogeneity and true state dependence. To capture only the latter, we follow Wooldridge (2005) and assume that

$$
\mu_{i}=\varphi_{3} \bar{X}_{i}+\varphi_{4} y_{i 0}+c_{i}
$$

where $\overline{X_{i}}$ denotes the mean value of the explanatory variables, $y_{i 0}$ the initial condition, and $c_{i}$ an individual specific error term. This yields

$$
y_{i t}^{*}=\varphi_{0}+\varphi_{1} y_{i t-1}+\varphi_{2} X_{i t}+\varphi_{3} \bar{X}_{i}+\varphi_{4} y_{i 0}+c_{i}+e_{i t}
$$

\footnotetext{
37 We could use additional lags of the explanatory variables as IVs but this would reduce our sample size considerably.

38 Note that as in any empirical study, there is the possibility that some of the $X_{i t}$ will be measured with error; for example, if this occurs in one of the personality indices then the IV estimator of $\beta_{1}$ will be biased through the correlation of the predicted $y_{i t-1}$ and the mismeasured variable. The bias will not be made any worse if the lagged value of the personality index is measured with error as long as the measurement error is uncorrelated over time; for example if each period's score for one of the personality indexes equals the true score plus an independent shock. Of course, there will be further bias if the measurement error in the personality index is correlated over time, since the the predicted $y_{i t-1}$ will be directly correlated with the error term in (5).
} 
We estimate this dynamic model by MLE where the estimate of $\varphi_{1}$ reflects only true state dependence. Note that restricting the initial condition to depend on the initial observation of the ED-BN index in our sample is less of a problem because have data on the respondents when they are young girls, and hence it seems reasonable to assume that $y_{i 0}$ does in fact capture initial conditions. ${ }^{39}$

As a robustness check we also estimate a dynamic Probit model (using the Wooldridge procedure) and a dynamic LPM for the incidence of the ED-BN index being greater than 10. We describe the models in more detail in the online Appendix (Goeree, Ham, and Iorio, 2009).

\subsection{Results for the Linear Model}

Table 6 contains our parameter estimates for the linear model. In column (1) we consider a model where the only explanatory variable is the (assumed to be exogenous) lagged dependent variable; its coefficient is estimated at 0.44 and, not surprisingly, it is very statistically significant. Regarding the effect of past ED-BN experience on current behavior, the coefficient can be interpreted as an elasticity since we would expect the mean of a variable and its lag to be equal. We obtain a relatively large estimate of the elasticity of 0.44 . To look at the magnitude of the coefficient in another way, an individual with a lagged ED-BN index of 5 would have a current ED-BN index over two points higher than someone with a lagged index of 0; this difference is almost $150 \%$ of the mean value of the ED-BN index. After we add the demographic variables and the personality indices in column (2) the lag coefficient drops to 0.35 and is insensitive to including body dissatisfaction in column (3). This demonstrates substantial persistence in BN behavior that can be due to both unobserved heterogeneity and true state dependence. To focus on the latter, in columns (4) and (5) we treat the lagged dependent variable as endogenous, and we estimate the levels equation by 2SLS using the time changing component of $X_{i t-1}$ as excluded IV. Column (4) reports a lagged coefficient of a little less than 0.19, suggesting that over half the variation in persistence attributed to unobserved heterogeneity and state dependence is actually due to the latter. ${ }^{40}$ This essentially suggests an elasticity of 0.2 for the

39 For more on the initial conditions issue, see Heckman (1981b). Further, while our data set allows one to estimate the dynamic models described above, one can imagine estimating even richer models with richer data. Specifically, given data on monthly BN behavior, we could estimate the hazard function for entering BN behavior or leaving BN in the same way that researchers estimate models of employment dynamics, such as in Eberwein, Ham and LaLonde (1997) and Ham, Li and Shore-Sheppard (2009). Further, one could use these estimates to look at duration dependence (after controlling for unobserved heterogeneity), or to estimate the effect of changing an explanatory variable on the expected duration of a BN (or non-BN) spell.

40 Some girls in our sample may receive treatment once they begin bulimic behavior, although we cannot identify who they are. If this treatment is even partially effective, it will reduce the degree of true state dependence, so our estimates are lower bounds on the degree of true state dependence in untreated BN. 
effect of lagged BN on current behavior. To put this another way, the expected ED-BN index for someone who has a lagged value of the ED-BN index equal to 5 compared to someone who has a lagged value of 0 would be higher by 1.0, approximately $80 \%$ of the mean value of $1.2 .{ }^{41}$ This result does not change if we include body dissatisfaction as an explanatory variable in column (5).

As is standard practice, we consider two diagnostics for our 2SLS estimates in columns (4) and (5). The first is a test statistic for weak instruments. In calculating this test we should take into account the fact that there will be heteroskedasticity in the first-stage regression equation for a censored dependent variable. Therefore the widely used rule of thumb for the first stage F-statistic of the excluded instruments from Staiger and Stock (1997) and Stock and Yogo (2005) will be inappropriate. Instead we use the conjecture by Hansen, Hausman, and Newey (2008) that in the presence of heteroskedasticity in the first stage equation, the Wald statistic for the null hypothesis that the excluded instruments are zero in the first stage, minus the number of instruments, should be greater than 32. Second, we present a Wald statistic to test the overidentifying restrictions that the instruments are valid; here the critical value is $\chi^{2}(l)$, where $l$ is the degree of overidentification. Intuitively the test can be thought of as assuming that one of the instruments is valid, and then seeing whether the other instruments have a zero coefficient in the structural equation. Also, we specifically test the validity of body dissatisfaction as an instrument, conditional on the other personality indices being valid, by entering its lagged value as an explanatory variable in column (5) and testing whether its coefficient is significantly different from zero. The diagnostics show that our instruments are not weak and the overidentifying restrictions, including that for body dissatisfaction in column (5), are not rejected.

The estimates in columns (4) and (5) are consistent if the individual effect is uncorrelated with the explanatory variables. As noted above, we also present the results of using the AB approach of differencing before using 2SLS. However, this approach may be too rich for the data since we lose a substantial number of observations, in part because the questions used to form the personality indices (excluding body dissatisfaction) were not asked in wave $7 .{ }^{42}$ To address this potential problem we assume that the personality index values vary smoothly from wave 5 to 9 , and we estimate the model using interpolated values of the personality indices in wave 7 , which doubles our sample size. To see whether this imputation is likely to affect our

41 Note that some girls in our sample will receive treatment once they begin to engage in BN behavior, although we cannot identify who they are. If this treatment is even partially effective, our substantial estimate is a lower bound for the persistence in untreated BN.

42 Specifically we lose the independent variables $\Delta X_{i t}$ when the dependent variable is $y_{i 9}-y_{i 7}$ and when the dependent variable is $y_{i 10}-y_{i 9}$. 
results, we present the 2SLS estimates of our basic model using the imputed data (with and without body dissatisfaction) in columns (6) and (7). Comparing the results in columns (6) and (7) to those in columns (4) and (5) respectively, indicates that using the imputed data diminishes the role of true state dependence by about one fifth, but that the coefficient on the lagged value is still highly significant. The results in column (8) show a highly significant lag coefficient of around 0.21 when we implement the AB approach on the imputed data. The coefficient estimates remain the same when we include body dissatisfaction as an explanatory variable in column (9). As noted above, we test the null hypothesis of no dependence in the residuals and cannot reject this null, indicating that our $\mathrm{AB}$ estimates are consistent.

In summary, we find that i) there is substantial persistence in $\mathrm{BN}$ and ii) over half of this persistence is due to true state dependence. Further, the magnitude of the effect suggests that it is quite important. These results are robust to changes in the explanatory variables and identification strategy.

So far we have focused on models where state dependence is constant across race and income class. Table 7 presents 2SLS estimates describing the racial and income differences in the persistence of $\mathrm{BN}$ when we address the endogeneity of past behavior. We use interpolated values for wave 7 (since we are estimating a richer model) and exclude body dissatisfaction as an explanatory variable. To facilitate the comparison with these results, column (1) repeats the results of Table 6 column (6), where the lag is not interacted with race or income. In the remaining columns we use the socioeconomic indicator of focus interacted with the lag of the perfectionism and ineffectiveness indices as IV. For example, in column (2) we allow the persistence to differ by race, where the IV are race interacted with the lagged personality indices. Column (2) indicates that much of the persistence in the overall sample is driven by the behavior of African American girls. Indeed, the estimate for persistence among Whites is very small and significant (0.05), while it is substantial and significant for African Americans (0.21). In column (3), where we consider income differences in persistence, we observe that the strongest persistence is in low income families, as the estimated coefficient on the lagged behavior is significant and very large at 0.32 (given we are instrumenting and imputing personality indices). It falls to 0.17 for middle income families and is essentially zero for girls from high income families. These results show interesting race and income effects of the persistence in BN behaviors, complementing our results from the static models. ${ }^{43}$

${ }^{43}$ The data are not rich enough to support estimating a model with full race-income interactions both in the levels and in the persistence. 


\subsection{Results for the Tobit and other Nonlinear Models}

The Tobit partial effect estimates are given in Table 8. Column (1) presents estimates of the model where the only explanatory variable is the lagged dependent variable, and the estimated partial effect is 0.27 . In column (2) we control for observable heterogeneity by including demographic variables and personality indices (except for body dissatisfaction), and the partial effect of the lagged dependent variable falls to 0.20. Column (3) includes body dissatisfaction as an explanatory variable, and the lag coefficient does not change. ${ }^{44}$ In order to control for unobserved heterogeneity in columns (4) and (5) we include correlated random effects using the $\mathrm{C} / \mathrm{W}$ approach, where we exclude and include body dissatisfaction, respectively. The estimates of 0.19 and 0.18 capture true state dependence, and represent about two-thirds of BN persistence, estimated at 0.27 in column (1), which reflects observed heterogeneity, unobserved heterogeneity, and true state dependence. Further, the persistence estimates in columns (4) and (5) are approximately equal to those in columns (2) and (3) respectively, suggesting that state dependence plays a much larger role than unobserved heterogeneity. ${ }^{45}$ The estimated partial effects from the Probit and LPM models are of similar sign to the linear and Tobit estimates, but fewer estimated coefficients are statistically significant. This is expected since the Probit and LPM use much less information per person. Indeed, our estimates illustrate the importance of not focusing on whether an individual has a clinical case of BN for understanding the determinants of the disorder. We report these results in our online Appendix (Goeree, Ham, and Iorio, 2009).

\section{BN State Dependence: Does it Reflect an Addiction?}

As discussed previously, this is the first quantitative attempt to separate individual heterogeneity from state dependence in bulimic behaviors. We find that up to two-thirds is due to true state dependence. Measuring addiction has a long tradition in economics. In this section, we further examine the potential addictive nature of $\mathrm{BN}$ as it relates to the medical definition of addiction. We believe that this is an interesting issue per se; moreover this discussion has substantial policy relevance.

We start by examining the medical definition of addiction and document a number of aspects of $\mathrm{BN}$ behavior that are consistent with it. According to the DSM-IV, in order to be classified

\footnotetext{
44 We also estimated the model for column (3) using the interpolated data, and these results (not shown) were very close to those for the non-imputed data presented in column (3).

${ }^{45}$ We do not interact the lagged dependent variable with race or income indicators, since a consistent estimator is not available for these models when we incorporate a fixed effect.
} 
as an addiction, a behavior or substance abuse must satisfy at least three of seven criteria in a given year: 1) experiencing a persistent desire for the substance or an inability to reduce or control its use, 2) tolerance (more is needed for the same effect), 3) use of the substance continuing despite known adverse consequences, 4) withdrawal, 5) taking a larger amount of the substance or taking the substance for a longer period, than was intended, 6) spending much time seeking or consuming the substance or recovering from its effects, and 7) use of the substance interfering with important activities. ${ }^{46}$

We focus on the first four criteria. It is straightforward to note that BN fulfills criterion 1 (inability to control its use) as one of the diagnostic criteria for BN involves loss of control over the eating process. ${ }^{47}$ Regarding criterion 2 our finding of true state dependence is a necessary condition for BN to exhibit tolerance. ${ }^{48}$ One could not reach this conclusion without using appropriate econometric techniques to distinguish between persistence due to true state dependence and that due to unobserved heterogeneity. ${ }^{49}$ However, we must consider competing explanations that generate state dependence in $\mathrm{BN}$, but that do not involve tolerance or increased use over time. For instance, it may be the case that individuals are initially uncertain of the deleterious side effects associated with bulimia, but they slowly learn through experimentation that $\mathrm{BN}$ is harmful. The slow learning explanation for state dependence has the implication that the longer girls have experienced bulimic behavior in the past the less likely they are to experience it in the future. To explore the potential for slow learning in explaining state dependence, we first consider an $\operatorname{AR}(2)$ process and then construct an "intensity" stock variable that is the sum of the ED-BN index over all previous periods. We also consider an alternative "threshold" stock in which past behavior contributes to the stock only if the girl

\footnotetext{
${ }^{46}$ Further, note that to be diagnosed with a physiological dependence it is necessary that either criteria 2 or 4 be met; thus physiological dependence is netiher necessary nor sufficient for the medical definition of addiction.

${ }^{47}$ In addition to loss of control over eating, in a recent study, Corwin and Grigson (2009) note that other diagnostic criteria for bingeing related disorders approximate the DSM-IV criteria for addiction. These include binge-type consumption, (i.e., criterion 5); bingeing is followed by inappropriate compensatory behavior (i.e., criterion 3); bingeing occurs at least twice a week for 3 months (i.e., criteria 5). Their argument is not based on an empirical analysis, but rather on their interpretation of the relation between the DSM-IV addiction and BN criteria.

${ }^{48}$ Increased behavior could either indicate that individuals are engaging more in the behavior to obtain i) the same effect over time (tolerance) or ii) stronger effects over time. Thus we say increased use is a necessary condition for tolerance, but not a sufficient one.

${ }^{49}$ As noted in Becker, et al. (1994), finding a positive and significant coefficient on past experience (after using instrumental variables to purge any effect of unobserved heterogeneity) is consistent with the hypothesis that the behavior under consideration is addictive. They study cigarette consumption and find an estimated coefficient on lagged behavior that is significant, positive, and less than 1 in an $\operatorname{AR}(1)$ process using IV techniques to address the endogeneity of lagged behavior. Note that this finding is neither necessary nor sufficient to satisfy the medical definition of addiction. Many other interesting theories of addiction have appeared in the literature, but we would need more information than we have in the data to empirically test them.
} 
engaged in more intense BN behavior in the past (defined as a value of the ED-BN greater than 6). ${ }^{50}$ The threshold stock reflects the idea that a person learns the harmful consequences of $\mathrm{BN}$ only when the intensity of the past behavior is relatively high. Note that while such stock measures could be problematic in samples with older individuals (as earlier BN behavior would be out of sample and thus unobserved), this is not an issue in our sample since the girls are quite young (ages 9-10) when first interviewed.

The results in Table 9 provide strong evidence against the slow learning interpretation of state dependence in BN. All results are based on 2SLS estimation where we treat the lagged ED-BN index as endogenous, include demographics and personality indices, exclude body dissatisfaction, and use interpolated values in wave 7. For comparison purposes, in the first column we repeat the results from column (6) of Table 6, which includes the first lag of ED-BN index. Column (2) specifies an $\mathrm{AR}(2)$ process where one and two lags of the personality indices are used as IV. Further, column (3) includes one lag of the ED-BN index and the intensity stock, while column (4) replaces the intensity stock with the threshold stock. In columns (3) and (4) we use the lag and the sum over all previous waves of each personality index as IV.

Our results in column (2) show that the first and second lag coefficients (recall that each lag is two years) are both statistically significant and equal to 0.12 and 0.11 , respectively. ${ }^{51}$ These results cast doubt on slow learning as a driving force in state dependence, as the latter suggests that experiencing $\mathrm{BN}$ for four years would most likely reduce current behavior. Further evidence against the learning interpretation comes from columns (3) and (4). If learning was important we would expect the coefficients on the stock variables to be negative and statistically significant, but instead they are both positive and insignificant. Thus we conclude that learning does not explain state dependence in the persistence of BN.

Further, in spite of negative health consequences (a number of which are readily apparent, such as inflammation and irritated esophagus, tooth decay, muscle weakness, gastric rupture, and anemia), we document that young women persist in bulimic behaviors. This behavior is consistent with addiction criterion 3 (i.e., use continues despite adverse consequences). Further, there is scientific evidence of withdrawal in BN behaviors. For example, Colton et al. (1998) find withdrawal symptoms in laxative use, which is considered to be a purging behavior, and this is consistent with criterion 4 . Thus based on our findings and medical evidence we argue that BN fulfills at least three (criteria 1, 3, and 4), and maybe four (criterion 2, tolerance), of the medical criteria hnecessary to be classified as an addiction.

50 There is not enough variation to consider an alternative stock in which past behavior contributes to the stock only if the ED-BN index is greater than 10.

51 The data are not rich enough to allow us to estimate an $\mathrm{AR}(3)$. 
This case can be made even stronger by noting that BN presents important similarities to drug and alcohol abuse. First, as noted above, medical research has found that starving, bingeing, and purging produces the same chemical effect as opiates. Second, again as noted above, opioid receptor binding in the area of the brain involving the anticipation and reward of eating in bulimic women is lower than in healthy women, and that this reaction has been found in other studies of addictive behavioral disorders, including drug addiction and gambling (Bencherif et al. 2005). Third, treatment for individuals with BN is most effective if given early in the illness. Indeed, the recovery rate is close to $80 \%$ if treated within the first 5 years; the rate falls to $20 \%$ if treatment is delayed until after 15 years (Reas et al., 2000). Finally, patients with $\mathrm{BN}$ seem to respond to treatment initially aimed at combatting drug and alcohol abuse. First, Naltrexone, an anti-addiction opioid antagonist normally used in the treatment of alcohol dependence, has shown signs of success in normalizing eating patterns in those suffering from anorexia and bulimia (Marrazzi 1995). Second, there are 12-step groups, such as Overeaters Anonymous, based on the recovery program of Alcoholics Anonymous.

Interpreting $\mathrm{BN}$ as an addiction has important policy implications. First, preventive educational programs should be targeted at young girls and coupled with more intense (rehabilitation) treatment at the early stages of bingeing and purging behaviors. Second, BN is currently considered a disorder, not an addiction. ${ }^{52}$ In the majority of the states treatment for alcoholism and drug addiction is covered (either by public or employer provided insurance) whereas treatment for ED is not covered in as many states (Center for Mental Health Services Report on State Parity Laws, 2008). However, it is difficult to see a reasonable justification for the different views of $\mathrm{BN}$ given our results.

\section{Conclusions}

This is the first study that quantifies the role of true state dependence and individual heterogeneity in bulimia nervosa and examines the potentially addictive nature of $\mathrm{BN}$ among adolescent girls. We use a panel data set, the NHLBI Growth and Health Survey, that is uniquely suited for studying these issues. A major advantage of these data is that all sample participants were evaluated regarding BN behaviors for ten years, starting when they were young (aged 9-10 years), independent of any diagnoses or treatment they had received. For each respondent the data contain i) an Eating Disorders Inventory index, developed by a panel of medical experts; ii) information on SES, and iii) information on personality characteristics.

\footnotetext{
${ }^{52}$ Families frequently have to fight to get the necessary treatment, and it is not uncommon to spend thousands of dollars out of pocket to pay for counseling and drugs NEDA(2008). Treatment involves individual and family therapy, behavior modification, nutritional rehabilitation and antidepressants (APA, 2000b).
} 
Our use of these data produces a number of important results. First, and perhaps most importantly, we find that much of the persistence in bulimic behavior is due to true state dependence after controlling for individual heterogeneity. Indeed we find that up to two-thirds of the persistence in $\mathrm{BN}$ is due to the true state dependence, and that the past four years of behavior positively and significantly impact bulimic behavior in the current period. We provide evidence that state dependence is not explained by slow learning about the harmful effects of $\mathrm{BN}$. We combine our results with other evidence in the medical literature to make the case that BN should be considered an addiction.

Surprisingly little is known about the (multivariate) factors determining the incidence of $\mathrm{BN}$, and we fill this gap in the literature. We find that income and race play crucial roles: African Americans are more likely to exhibit and persist in bulimic behavior. Indeed, the estimates suggest that the impact of past behavior on current behavior is four-fold higher among African Americans. In addition, the incidence of $\mathrm{BN}$ is decreasing in income, and the strongest persistence (among income groups) is present in low income families. These results stand in stark contrast to the popular conceptions about who suffers from BN. Based on evidence here and in Goeree, Ham, and Iorio (2008), we argue that this disparity occurs because affluent White teenage girls are much more likely to be diagnosed with BN conditional on having it.

Our paper suggests that when a diagnosis is based on an underlying index using all the information contained in the index, in addition to the zero-one diagnosis, can be very helpful to applied researchers in obtaining precise parameter estimates. Our findings show the usefulness of using appropriate econometric techniques for investigating medical issues from survey data. Our estimates are robust to different estimation methods and identifying assumptions.

Our results have several important policy implications. First, substantial outreach concerning BN should be made to low income girls, especially African Americans. Second, since state dependence is the most important cause of the persistence in $\mathrm{BN}$, it is reasonable to expect that the longer an individual experiences BN the less responsive she will be to policy aimed at combatting the behavior. In this respect it is important to instruct a wide range of young women on the deleterious effects of $\mathrm{BN}$ and the importance of getting help, especially at the initial stages of bulimic behaviors. Third, our results strongly suggest that BN should be treated as an addiction, rather than only as a disorder, as is currently the case. This change would put those exhibiting $\mathrm{BN}$ on equal footing (from a treatment reimbursement perspective) with individuals abusing drugs or alcohol. In the majority of the states treatment for alcoholism and drug addiction is covered whereas treatment for ED is not covered in as many states (Center for Mental Health Services Report on State Parity Laws, 2008), and when available the coverage can be inadequate. 


\section{References}

American Psychiatric Association (APA) (1993) "Practice Guideline for Eating Disorders" American Journal of Psychiatry 150: 212-228.

American Psychiatric Association (APA) (2000a) Diagnostic and Statistical Manual of Mental Disorders American Psychiatric Press: Washington DC. 4th Edition.

American Psychiatric Association (APA) (2000b) "Practice Guideline for the Treatment of Patients with Eating Disorders (Revision)" American Journal of Psychiatry 15: 1-39.

Anderson, T.W., and C. Hsiao (1981), "Estimation of Dynamic Models with Error Components" Journal of the American Statistical Association 76: 598-606.

Arellano and Bond (1991) "Some Tests of Specification for Panel Data: Monte Carlo Evidence and an Application to Employment Equations" Review of Economic Studies 58: $277-97$.

Baltagi B., and J. Griffin (2001) "The Econometrics of Rational Addiction: The Case of Cigarettes" Journal of Business \&3 Economic Statistics 19: 449-454.

Becker, G.S. and K.M. Murphy (1988) "A Theory of Rational Addiction" Journal of Political Economy 94: 675-700.

Becker, G.S., M. Grossman, and K.M. Murphy (1994) "An Empirical Analysis of Cigarettes Addiction" American Economic Review 84: 396-418.

Bencherif B., A.S. Guarda, C. Colantuoni, H. Ravert, R. Dannals, and J. Frost (2005) "Regional $\mu$-Opioid Receptor Binding in Insular Cortex is Decreased in Bulimia Nervosa and Correlates Inversely with Fasting Behavior" The Journal of Nuclear Medicine 46: 1349-1351.

Borghans, L., A. Duckworth, J. Heckman, and B. ter Weel (2008) "The Economics and Psychology of Personality Traits," Journal of Human Resources 43(4): 972-1052.

Bulik, C., B. Devlin, and S. Bacanu (2003) "Significant Linkage on Chromosome 10p in Families with Bulimia Nervosa" American Journal of Human Genetics 72: 200-207.

Cavanaugh, C. and L. Ray (1999) "What we know about eating disorders: facts and statistics" In Lemberg, Raymond and Cohn, Leigh (Eds) Eating Disorders: A Reference Sourcebook. Oryx. Press. Phoenix, AZ.

Cawley, J. (2001) "Addiction and the Consumption of Calories: Implications for Obesity" NBER Working Paper.

Center for Mental Health Services (2008), Report on State Parity Laws URL: http://download.ncadi.samhsa.gov/Ken/pdf/SMA074228/CMHS17a_StateMandates_web.pdf 
Chaloupka F. and Warner (2000) "The Economics of Smoking" in Handbook of Health Economics . North Holland.

Chamberlain G. (1984) "Panel Data" in Z. Griliches and M.D. Intriligator (eds.), Handbook of Econometrics, Volume 2. Amsterdam: North Holland, 1247-1318.

Colton, P., D. Woodside, and A. Kaplan (1998) "Laxative Withdrawal in Eating Disorders: Treatment Protocol and 3 to 20-Month Follow-up" International Journal of Eating Disorders 25(3): 311-317.

Corwin, R. and P.Grigson (2009) "Food Addiction: Fact or Fiction?" The Journal of Nutrition 139(3): 617-619.

Department of Health and Human Services (2006) Agency for Healthcare Research and Quality, Management of Eating Disorders, Evidence Report/Technology Assessment, Number 135, 2006. AHRQ publication 06-E010. Senate Report accompanying the 2006 budget as reported by the Eating Disorders Coalition. URL: www.eatingdisorderscoalition.org.

Erberwein, C., J. Ham, and R. LaLonde (1997) "The Impact of Being Offered and Receiving Classroom Training on the Employment Histories of Disadvantaged Women: Evidence From Experimental Data" Review of Economic Studies 64(4): 655-682.

Fitcher, M. and N. Quadflieg (1997) "Six-year Course of Bulimia Nervosa" International Journal of Eating Disorders 22(4): 361-84.

Garner, D., P. Marion, M.A. Olmstead, and J. Polivy (1983) "Development and Validation of a Multidimensional Eating Disorder Inventory for Anorexia Nervosa and Bulimia" International Journal of Eating Disorders 2: 15-34.

Gilleskie, D.B. and K. S. Strumpf (2005) "The Behavioral Dynamics of Youth Smoking" Journal of Human Resources 40: 822-866.

Goeree, M., J. Ham and D. Iorio (2008) "An Economic Analysis of Eating Disorders Behaviors" mimeo, University of Southern California.

Goeree, M., J. Ham and D. Iorio (2009) "Online Appendices to Caught in the Bulimic Trap: Socioeconomic Status, State Dependence, and Unobserved Heterogeneity" URL: http://www-rcf.usc.edu/ goeree/addictive trap supplement.pdf.

Ham , J., X. Li, and L. Shore-Sheppard. (2009) "Correcting for Seam Bias when Estimating Multiple-State, Multiple-Spell Duration Models, with an Application to Analyzing the Employment Dynamics of Disadvantaged Women in the SIPP," Mimeo, University of Maryland.

Hansen, C., J. Hausman and W. Newey (2008) "Estimation with Many Instrumental Variables" Journal of Business and Economic Statistics 26(4): 398-422.

Heckman, J. (1981a) "Heterogeneity and State Dependence" In Sherwin Rosen (Eds), Studies in Labor Markets, Chicago: University of Chicago Press. 
Heckman, James J. (1981b)"The Incidental Parameters Problem and the Problem of Initial Conditions in Estimating a Discrete Time-Discrete Data Stochastic Process and Some Monte Carlo Evidence" In C.Manski and D. McFadden (eds.), Structural Analysis of Discrete Data With Econometric Applications, (M.I.T. Press).

House of Representatives (2008) 6983, 110th Congress, Paul Wellstone and Pete Domenici Mental Health Parity and Addiction Equity Act of 2008

Hudson, J., E. Hiripi, H. Pope Jr, and R. Kesslre (2007) "The Prevalence and Correlates of Eating Disroders in the National Comorbidity Survey Replication" Biological Psychiatry 61: $348-358$.

Keel, P., D. Dorer, D. Franko, S. Jackson, S., and D. Herzog (2005) "Postremission Predictors of Relapse in Women with Eating Disorders" American Journal of Psychiatry 162: 2263-2268.

Kimm, S., B. Barton, E. Obarzanek, et al. (2002) "Obesity Development During Adolescence in a Biracial Cohort: The NHLBI Growth and Health Study" Pediatrics 110: e54.

Labeaga, J. and A. Jones (2003) "Individual heterogeneity and censoring in panel data estimates of tobacco expenditures" Journal of Applied Econometrics 18(2): 157-77.

Lauderdale, D. and P. Rathouz (2000) "Body Mass Index in a U.S. National Sample of Asian Americans: Effects of Nativity, Years since Immigration and Socioeconomic Status" International Journal of Obesity and Related Metabolical Diseases 24: 1188-94.

Lilenfeld, L., W. Kaye, and C. Greeno (1998) "A Controlled Family Study of Restricting Anorexia and Bulimia Nervosa: Comorbidity in Probands and Disorders in First-Degree Relatives" Archives of General Psychiatry 55: 603-10.

Mangweth, B., J. Hudson, H. Pope Jr., A. Hausmann, C. De Col, and N. Larid (2003) "Family Study of the Aggregation of Eating Disorders and Modd Disorders" Psychological Medicine 33: 1319-1323.

Marrazzi, M. JP Bacon, J Kinzie, ED Luby (1995) "Naltrexone use in the treatment of anorexia nervosa and bulimia nervosa," International Clinical Psychopharmacology (1995), 10, $163-172$.

National Eating Disorders Association (2008) URL: www.nationaleatingdisorders.org. Accessed Dec 29, 2008.

National Youth Risk Behavior Survey (2005) URL: http://www.cdc.gov/HealthyYouth/yrbs/index.htm.

O'Dea, J. and S. Abraham (2000) "Improving the body dissatisfaction, Eating Attitudes, and Behaviors of Young Male and Female Adolescents: a New Educational Approach that Focuses on Self-Esteem" International Journal of Eating Disorders 28(1):43-57. 
Rashad, I. (2006) "Structural Estimation of Caloric Intake, Exercise, Smoking, and Obesity" Quarterly Review of Economics and Finance 46(2): 268-283.

Reagan, P. and J. Hersch (2005) "Influence of Race, Gender, and Socioeconomic Status on Binge Eating Frequency in a Population-Based Sample" International Journal of Eating Disorders 38: 252-256.

Reas, D., D.Williamson, C. Martin, and N. Zucker (2000) "Duration of Illness Predicts Outcome for Bulimia Nervosa: A Long-term Follow-up Study" International Journal of Eating Disorders 27: 428-34.

Reeder, B., Y. Chen, and S. Macdonal (1997) "Regional and Rural-Urban Differences in Obesity in Canada" Canadian Medical Association Journal 157: 1510-6.

Daly, Rich (2008) "Few States Act on Parity Improvements This Year" Psychiatry News 43: 2-25.

Richards, T., P. Patterson, and A. Tegene (2007) Obesity and Nutrient Consumption: A Rational Addiction?" Contemporary Economic Policy 25: 309-324.

Robinson, T., Chang, J., Haydel, K. (2001) "Overweight Concerns and Body Dissatisfaction among Third Grade Children: the Impacts of Ethnicity and Socioeconomic Status" Journal of Pediatrics 138: 181-7.

Rush, J., M. First, and D. Blacker (2008) Handbook of Psychiatric Measures American Psychiatric Publishing: Arlington, VA, 2nd Edition.

School Health Profiles (2004) US Department of Health and Human Services, Centers for Disease Control. URL: http://www.cdc.gov/healthyYouth/profiles/

Society for Adolescent Medicine (2003) "Eating Disorders in Adolescents: Position Paper of the Society for Adolescent Medicine" Journal of Adolescent Health 33: 496-503.

Staiger D. and J. Stock (1997) "Instrumental Variables Regression with Weak Instruments" Econometrica 65: 557-586.

Striegel-Moore, R.G., G. Schreiber, A. Lo, P. Crawford, E. Obarzanek, and J. Rodin (2000) "Eating Disorder Symptoms in a Cohort of 11 to 16-Year-Old Black and White Girls: The NHLBI Growth and Health Study," International Journal of Eating Disorders, 27:49-66.

Stock, J. and M. Yogo (2005) "Testing for Weak Instruments" Chapter 5, in Identification and Inference for Econometric Models: Essays in Honor of Thomas Rothenberg Andrews, D.W.K. and J.H. Stock eds. Cambride University Press.

Vandereycken, W. (2006) "The Addiction Model in Eating Disorders: Some Critical Remarks and a Selected Bibliography" International Journal of Eating Disorders 9(1): 95 101. 
Walters, E., Nealed, M., Eaves, L., Heath, A., Kessler, R., and K. Kendler (1992) "Bulimia Nervosa and Major Depression: a Study of Common Genetic and Envrionmental Factors" Psychological Medicine 22: 617-622.

Wooldridge, J.M. (2002) Econometric Analysis of Cross Section and Panel Data. MIT Press.

Wooldridge, J.M. (2005), "Simple Solutions to the Initial Conditions Problem in Dynamic, Nonlinear Panel Data Models with Unobserved Effects" Journal of Applied Econometrics 20: $39-54$.

\section{Tables}

Table 1: Descriptive Statistics

\begin{tabular}{lcccc}
\hline & Mean & $\begin{array}{c}\text { Standard } \\
\text { Deviation }\end{array}$ & $\begin{array}{c}\text { Clustered Standard } \\
\text { Error of Mean }\end{array}$ & $\begin{array}{c}\text { Number of } \\
\text { Waves }\end{array}$ \\
\hline ED-BN Index & 1.279 & 2.682 & 0.039 & $3,5,7,9,10$ \\
Clinical Bulimia & 0.022 & 0.145 & 0.002 & $3,5,7,9,10$ \\
Age & 14.363 & 2.991 & 0.014 & All 10 \\
White & 0.480 & 0.499 & 0.010 & 1 \\
Parents High School or Less & 0.255 & 0.436 & 0.009 & 1 \\
Parents Some College & 0.393 & 0.488 & 0.010 & 1 \\
Parents Bachelor Degree or More & 0.352 & 0.477 & 0.010 & 1 \\
Income less than \$20,000 & 0.318 & 0.466 & 0.010 & 1 \\
Income in [\$20000, \$40000] & 0.315 & 0.465 & 0.010 & 1 \\
Income more than $\$ 40,000$ & 0.367 & 0.482 & 0.010 & $3,5,7,9,10$ \\
Body Dissatisfaction Index* & 8.039 & 7.554 & 0.131 & $3,5,9,10$ \\
Distrust Index** & 3.589 & 3.492 & 0.056 & $3,5,9,10$ \\
Ineffectiveness Index*** & 2.752 & 3.915 & 0.063 & $3,5,9,10$ \\
Perfectionism Index**** & 6.468 & 3.290 & 0.052 & 1 \\
\hline Nots: Ins & &
\end{tabular}

Notes: Income is in 1988\$; * ranges from 0 to 27 (maximal dissatisfaction); ** ranges from 0 to 21 (maximal distrust);

*** ranges from 0 to 29 (maximal ineffectiveness); ${ }^{* * * *}$ ranges from 0 to 18 (maximal perfectionism). See Appendix for more detailed description of the variables. 
Table 2: Mean of ED-BN Index and Incidence of Clinical Bulimia by Characteristics

\begin{tabular}{lcccccc}
\hline \multicolumn{1}{c}{ Variable } & \multicolumn{3}{c}{ ED-BN Index } & \multicolumn{3}{c}{ Clinical Bulimia (BN) } \\
& Mean & $\begin{array}{c}\text { Standard } \\
\text { Deviation }\end{array}$ & $\begin{array}{c}\text { Clustered } \\
\text { Std. Error }\end{array}$ & Mean & $\begin{array}{c}\text { Standard } \\
\text { Clustered } \\
\text { Deviation }\end{array}$ & Std. Error \\
\hline Years: & & & & & & \\
1989 & 1.814 & 3.287 & 0.070 & 0.038 & 0.191 & 0.004 \\
1991 & 1.610 & 3.021 & 0.067 & 0.033 & 0.178 & 0.004 \\
1993 & 1.098 & 2.342 & 0.054 & 0.014 & 0.117 & 0.003 \\
1995 & 0.860 & 2.054 & 0.046 & 0.008 & 0.092 & 0.002 \\
1996 & 0.955 & 2.279 & 0.050 & 0.013 & 0.113 & 0.002 \\
White & 1.042 & 2.437 & 0.051 & 0.017 & 0.130 & 0.002 \\
African American & 1.498 & 2.873 & 0.058 & 0.026 & 0.158 & 0.003 \\
Parents High School or Less & 1.648 & 3.136 & 0.096 & 0.033 & 0.178 & 0.005 \\
Parents Some College & 1.325 & 2.682 & 0.060 & 0.020 & 0.141 & 0.003 \\
Parents Bachelor Degree or More & 0.973 & 2.278 & 0.055 & 0.015 & 0.122 & 0.002 \\
Household Income (in 1988\$): & & & & & & 0.004 \\
Income less than \$20,000 & 1.721 & 3.146 & 0.086 & 0.033 & 0.179 & 0.003 \\
Income in [\$20000, \$40000] & 1.198 & 2.633 & 0.072 & 0.021 & 0.144 & 0.003 \\
Income more than \$40,000 & 0.982 & 2.245 & 0.053 & 0.013 & 0.112 & 0.002 \\
\hline
\end{tabular}

Correlations of ED-BN Index and Clinical Bulimia with Personality Characteristics

Personality Characteristic Index ED-BN Index

Clinical Bulimia (BN)

$\begin{array}{lll}\text { Body Dissatisfaction Index } & 0.221 & 0.114 \\ \text { Distrust Index } & 0.213 & 0.107 \\ \text { Ineffectiveness Index } & 0.439 & 0.274 \\ \text { Perfectionism Index } & 0.229 & 0.145\end{array}$

Notes: The top panel reports clustered standard errors of the mean. All correlations in the bottom panel are significant at the $1 \%$ level.

Table 3: ED-BN Index Transition Probabilities

\begin{tabular}{c|cccc} 
& \multicolumn{4}{|c}{ ED-BN Index Range at $\mathrm{t}+1$} \\
\hline ED-BN Index Range at $\mathrm{t}$ & 0 & {$[1,5]$} & {$[6,10]$} & $>10$ (Clinical BN) \\
\hline 0 & 80.16 & 17.90 & 1.50 & 0.43 \\
{$[1,5]$} & 51.92 & 39.80 & 6.47 & 1.82 \\
{$[6,10]$} & 31.38 & 42.86 & 17.80 & 7.96 \\
$>10($ Clinical BN) & 21.93 & 37.97 & 20.32 & 19.79 \\
\hline Marginal Probability & & & & 1.67 \\
of ED-BN Index at t+1 & 68.57 & 25.59 & 4.17 &
\end{tabular}


Table 4: The (Partial) Effects of Demographic Variables on BN

\begin{tabular}{|c|c|c|c|c|}
\hline & \multicolumn{2}{|c|}{ ED-BN Index } & \multicolumn{2}{|c|}{ Clinical Bulimia } \\
\hline & $\begin{array}{l}\text { Linear } \\
\text { Model } \\
\end{array}$ & Tobit & Probit & $\begin{array}{c}\text { Linear } \\
\text { Probability }\end{array}$ \\
\hline White & $\begin{array}{c}-0.243^{* * *} \\
(0.088)\end{array}$ & $\begin{array}{c}-0.220 * * * \\
(0.078)\end{array}$ & $\begin{array}{l}-0.003 \\
(0.004)\end{array}$ & $\begin{array}{l}-0.004 \\
(0.004)\end{array}$ \\
\hline Age & $\begin{array}{c}-0.132^{* * *} \\
(0.011)\end{array}$ & $\begin{array}{c}-0.104 * * * \\
(0.009)\end{array}$ & $\begin{array}{c}-0.004 * * * \\
(0.001)\end{array}$ & $\begin{array}{c}-0.004 * * * \\
(0.001)\end{array}$ \\
\hline Parents Some College & $\begin{array}{c}-0.198^{*} \\
(0.113)\end{array}$ & $\begin{array}{l}-0.104 \\
(0.090)\end{array}$ & $\begin{array}{l}-0.006^{*} \\
(0.003)\end{array}$ & $\begin{array}{l}-0.010^{*} \\
(0.005)\end{array}$ \\
\hline $\begin{array}{l}\text { Parents Bachelor Degree } \\
\text { or More }\end{array}$ & $\begin{array}{c}-0.313^{* * *} \\
(0.116)\end{array}$ & $\begin{array}{c}-0.225^{* *} \\
(0.100)\end{array}$ & $\begin{array}{l}-0.005 \\
(0.004)\end{array}$ & $\begin{array}{l}-0.008 \\
(0.005)\end{array}$ \\
\hline Income in $[\$ 20000, \$ 40000]$ & $\begin{array}{c}-0.377 * * * \\
(0.112)\end{array}$ & $\begin{array}{c}-0.324 * * * \\
(0.087)\end{array}$ & $\begin{array}{l}-0.005 \\
(0.003)\end{array}$ & $\begin{array}{c}-0.009 * \\
(0.005)\end{array}$ \\
\hline Income more than $\$ 40,000$ & $\begin{array}{c}-0.488^{* * * *} \\
(0.107)\end{array}$ & $\begin{array}{c}-0.405^{* * *} \\
(0.091)\end{array}$ & $\begin{array}{c}-0.013 * * * \\
(0.004)\end{array}$ & $\begin{array}{c}-0.016 * * * \\
(0.005)\end{array}$ \\
\hline \multicolumn{5}{|l|}{ Year Dummies Included } \\
\hline White & $\begin{array}{c}-0.227 * * * \\
(0.088)\end{array}$ & $\begin{array}{c}-0.205^{* * *} \\
(0.078)\end{array}$ & $\begin{array}{l}-0.003 \\
(0.003)\end{array}$ & $\begin{array}{l}-0.004 \\
(0.004)\end{array}$ \\
\hline Age & $\begin{array}{c}0.010 \\
(0.060)\end{array}$ & $\begin{array}{c}0.040 \\
(0.057)\end{array}$ & $\begin{array}{l}-0.004 \\
(0.002)\end{array}$ & $\begin{array}{l}-0.005^{*} \\
(0.003)\end{array}$ \\
\hline Parents Some College & $\begin{array}{c}-0.193 * \\
(0.113)\end{array}$ & $\begin{array}{l}-0.101 \\
(0.090)\end{array}$ & $\begin{array}{l}-0.006^{*} \\
(0.003)\end{array}$ & $\begin{array}{l}-0.009 * \\
(0.005)\end{array}$ \\
\hline $\begin{array}{l}\text { Parents Bachelor Degree } \\
\text { or More }\end{array}$ & $\begin{array}{c}-0.299 * * * \\
(0.116)\end{array}$ & $\begin{array}{c}-0.211^{* *} \\
(0.100)\end{array}$ & $\begin{array}{l}-0.005 \\
(0.004)\end{array}$ & $\begin{array}{l}-0.008 \\
(0.005)\end{array}$ \\
\hline Income in $[\$ 20000, \$ 40000]$ & $\begin{array}{c}-0.384 * * * \\
(0.112)\end{array}$ & $\begin{array}{c}-0.330 * * * \\
(0.086)\end{array}$ & $\begin{array}{l}-0.005 \\
0.003\end{array}$ & $\begin{array}{l}-0.009 \\
(0.005)\end{array}$ \\
\hline Income more than $\$ 40,000$ & $\begin{array}{c}-0.500^{* * *} \\
(0.106)\end{array}$ & $\begin{array}{c}-0.416 * * * \\
(0.090)\end{array}$ & $\begin{array}{c}-0.013 * * * \\
(0.004)\end{array}$ & $\begin{array}{c}-0.016 * * * \\
(0.005)\end{array}$ \\
\hline Sample Size & 9591 & 9591 & 9591 & 9591 \\
\hline
\end{tabular}

Notes: Standard errors robust to both heteroskedasticity and intra-individual correlation are in parenthesis in columns (1) and (4). Standard errors robust to intra-individual correlation are in parenthesis in (2) and (3). * indicates significant at the 10\% level; ** at the $5 \%$ level; ${ }^{* * *}$ at the $1 \%$ level. 
Table 5: Estimates of the Effect of Demographic Variables and Personality Indices on the ED-BN Index

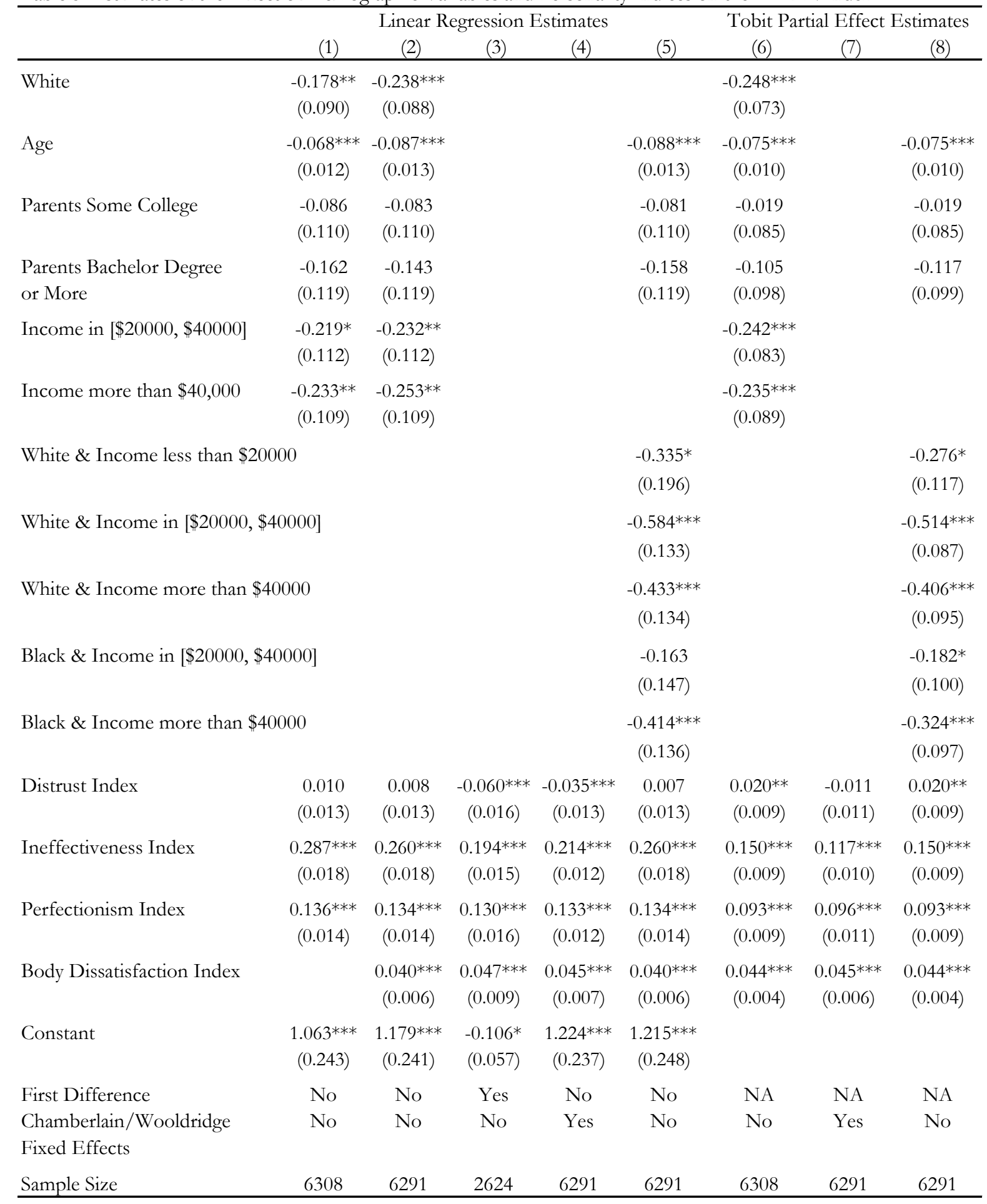

Notes: Standard errors robust intra-individual correlation (and robust to heteroskedasticity for linear regressions)

are in parentheis. ${ }^{*}$ indicates significant at the $10 \%$ level; ** at $5 \%$; *** at $1 \%$. The variation in the sample size comes primarily from the fact that all personality indices but the body image index are not available in wave 7 . 
Table 6: Linear Regression Estimates of the Persistence of ED-BN Index

\begin{tabular}{|c|c|c|c|c|c|c|c|c|c|}
\hline \multirow[t]{2}{*}{ Variables } & \multirow[b]{2}{*}{$(1)$} & \multirow[b]{2}{*}{$(2)$} & \multirow[b]{2}{*}{ (3) } & \multicolumn{4}{|c|}{ Two Stage Least Squares } & \multicolumn{2}{|c|}{ Arellano-Bond } \\
\hline & & & & (4) & $(5)$ & $(6)$ & $(7)$ & $(8)$ & $(9)$ \\
\hline Lagged ED-BN Index & $\begin{array}{c}0.444^{* * *} \\
(0.028)\end{array}$ & $\begin{array}{c}0.355^{* * *} \\
(0.027)\end{array}$ & $\begin{array}{c}0.349 * * * \\
(0.027)\end{array}$ & $\begin{array}{c}0.190^{* * *} \\
(0.048)\end{array}$ & $\begin{array}{c}0.188^{* * *} \\
(0.046)\end{array}$ & $\begin{array}{c}0.149 * * * \\
(0.035)\end{array}$ & $\begin{array}{c}0.131^{* * *} \\
(0.033)\end{array}$ & $\begin{array}{c}0.209 * * * \\
(0.022)\end{array}$ & $\begin{array}{c}0.209 * * * \\
(0.022)\end{array}$ \\
\hline White & & $\begin{array}{l}-0.038 \\
(0.085)\end{array}$ & $\begin{array}{l}-0.081 \\
(0.084)\end{array}$ & $\begin{array}{l}-0.105 \\
(0.120)\end{array}$ & $\begin{array}{l}-0.174 \\
(0.120)\end{array}$ & $\begin{array}{l}-0.134 * \\
(0.069)\end{array}$ & $\begin{array}{c}-0.201 * * * \\
(0.070)\end{array}$ & & \\
\hline Age & & $\begin{array}{c}-0.051 * * * \\
(0.016)\end{array}$ & $\begin{array}{c}-0.063^{* * *} \\
(0.016)\end{array}$ & $\begin{array}{l}-0.021 \\
(0.025)\end{array}$ & $\begin{array}{l}-0.032 \\
(0.025)\end{array}$ & $\begin{array}{c}-0.065^{* * *} \\
(0.016)\end{array}$ & $\begin{array}{c}-0.080 * * * \\
(0.016)\end{array}$ & $\begin{array}{c}-0.390 * * * \\
(0.133)\end{array}$ & $\begin{array}{c}-0.453 * * * \\
(0.133)\end{array}$ \\
\hline Parents Some College & & $\begin{array}{c}0.073 \\
(0.101)\end{array}$ & $\begin{array}{c}0.073 \\
(0.101)\end{array}$ & $\begin{array}{c}0.017 \\
(0.144)\end{array}$ & $\begin{array}{l}-0.006 \\
(0.143)\end{array}$ & $\begin{array}{l}-0.066 \\
(0.081)\end{array}$ & $\begin{array}{l}-0.089 \\
(0.081)\end{array}$ & & \\
\hline $\begin{array}{l}\text { Parents Bachelor Degree } \\
\text { or More }\end{array}$ & & $\begin{array}{c}0.122 \\
(0.110)\end{array}$ & $\begin{array}{c}0.131 \\
(0.110)\end{array}$ & $\begin{array}{l}-0.009 \\
(0.164)\end{array}$ & $\begin{array}{l}-0.011 \\
(0.163)\end{array}$ & $\begin{array}{l}-0.035 \\
(0.092)\end{array}$ & $\begin{array}{l}-0.040 \\
(0.092)\end{array}$ & & \\
\hline Income in $[\$ 20000, \$ 40000]$ & & $\begin{array}{c}-0.236^{* *} \\
(0.102)\end{array}$ & $\begin{array}{c}-0.238^{* *} \\
(0.102)\end{array}$ & $\begin{array}{c}-0.524 * * * \\
(0.147)\end{array}$ & $\begin{array}{c}-0.539 * * * \\
(0.146)\end{array}$ & $\begin{array}{c}-0.240^{* * *} \\
(0.083)\end{array}$ & $\begin{array}{c}-0.248^{* * *} \\
(0.083)\end{array}$ & & \\
\hline Income more than $\$ 40,000$ & & $\begin{array}{c}-0.207 * * \\
(0.104)\end{array}$ & $\begin{array}{c}-0.221 * * \\
(0.103)\end{array}$ & $\begin{array}{c}-0.463 * * * \\
(0.158)\end{array}$ & $\begin{array}{c}-0.486 * * * \\
(0.157)\end{array}$ & $\begin{array}{c}-0.288^{* * *} \\
(0.089)\end{array}$ & $\begin{array}{c}-0.296 * * * \\
(0.089)\end{array}$ & & \\
\hline Distrust Index & & $\begin{array}{l}-0.019 \\
(0.014)\end{array}$ & $\begin{array}{l}-0.018 \\
(0.014)\end{array}$ & $\begin{array}{c}-0.040^{* *} \\
(0.017)\end{array}$ & $\begin{array}{c}-0.041^{* *} \\
(0.017)\end{array}$ & $\begin{array}{l}-0.002 \\
(0.010)\end{array}$ & $\begin{array}{l}-0.002 \\
(0.010)\end{array}$ & $\begin{array}{l}-0.013 \\
(0.020)\end{array}$ & $\begin{array}{l}-0.017 \\
(0.020)\end{array}$ \\
\hline Ineffectiveness Index & & $\begin{array}{c}0.205^{* * *} \\
(0.020)\end{array}$ & $\begin{array}{c}0.188^{* * *} \\
(0.020)\end{array}$ & $\begin{array}{c}0.258^{* * *} \\
(0.017)\end{array}$ & $\begin{array}{c}0.229 * * * \\
(0.017)\end{array}$ & $\begin{array}{c}0.230 * * * \\
(0.012)\end{array}$ & $\begin{array}{c}0.206^{* * *} \\
(0.011)\end{array}$ & $\begin{array}{c}0.183^{* * *} \\
(0.018)\end{array}$ & $\begin{array}{c}0.162^{* * *} \\
(0.019)\end{array}$ \\
\hline Perfectionism Index & & $\begin{array}{c}0.097 * * * \\
(0.013)\end{array}$ & $\begin{array}{c}0.095^{* * *} \\
(0.013)\end{array}$ & $\begin{array}{c}0.129 * * * \\
(0.016)\end{array}$ & $\begin{array}{c}0.125^{* * *} \\
(0.016)\end{array}$ & $\begin{array}{c}0.096^{* * *} \\
(0.010)\end{array}$ & $\begin{array}{c}0.093^{* * *} \\
(0.010)\end{array}$ & $\begin{array}{c}0.131 * * * \\
(0.019)\end{array}$ & $\begin{array}{c}0.129 * * * \\
(0.019)\end{array}$ \\
\hline Body Dissatisfaction Index & & & $\begin{array}{c}0.027 * * * \\
(0.005)\end{array}$ & & $\begin{array}{c}0.040^{* * *} \\
(0.008)\end{array}$ & & $\begin{array}{c}0.036^{* * *} \\
(0.004)\end{array}$ & & $\begin{array}{c}0.052^{* * *} \\
(0.009)\end{array}$ \\
\hline Constant & $\begin{array}{c}0.597 * * * \\
(0.037)\end{array}$ & $\begin{array}{l}0.592^{*} \\
(0.304)\end{array}$ & $\begin{array}{c}0.657^{* *} \\
(0.303)\end{array}$ & $\begin{array}{c}0.515 \\
(0.414)\end{array}$ & $\begin{array}{c}0.538 \\
(0.410)\end{array}$ & $\begin{array}{c}1.138^{* * *} \\
(0.285)\end{array}$ & $\begin{array}{c}1.233^{* * *} \\
(0.285)\end{array}$ & $\begin{array}{c}0.558^{* * *} \\
(0.250)\end{array}$ & $\begin{array}{c}0.640^{* * *} \\
(0.253)\end{array}$ \\
\hline Interpolated Indices & No & No & No & No & No & Yes & Yes & Yes & Yes \\
\hline Weak IV Test & NA & NA & NA & 143.20 & 164.76 & 221.89 & 265.947 & & \\
\hline Overidentification Test & NA & NA & NA & 3.227 & 4.019 & 7.485 & 9.584 & NA & NA \\
\hline First Difference & No & No & No & No & No & No & No & Yes & Yes \\
\hline Sample Size & 4151 & 3938 & 3928 & 2285 & 2273 & 5426 & 5384 & 3437 & 3411 \\
\hline
\end{tabular}

Notes: Standard errors robust to heteroskedasticity and intra-group correlation are reported in parenthesis. NA denotes not applicable;

$*$ indicates significant at $10 \%$; ${ }^{*}$ significant at $5 \%$; $* *$ significant at $1 \%$. Instruments are one-period lags of: all personality indices in

columns (5) and (7); all indices excluding body dissatisfaction in columns (4) and (6). Regarding the weak IV test, the test statistic should be greater than 32. Regarding the overidentifying test, under the null hypothesis that the overidentifying restrictions are satisified the test statistic should be distributed Chi-Squared(2) and (Chi-Square(3)) in columns (4) and (6) (columns (5)and (7)). The model in columns (8) and (9) are exactly identified. Columns (6)- (9) use interpolated values of personality indices in wave 7. 
Table 7: Racial and Income Class Differences in the Persistence of BN

\begin{tabular}{|c|c|c|c|}
\hline & \multicolumn{3}{|c|}{ Two-Stage Least Squares Estimates } \\
\hline & $(1)$ & $(2)$ & (3) \\
\hline White & $\begin{array}{c}-0.134 * \\
(0.069)\end{array}$ & $\begin{array}{c}0.058 \\
(0.093)\end{array}$ & $\begin{array}{c}-0.129 * \\
(0.069)\end{array}$ \\
\hline Age & $\begin{array}{c}-0.065^{* * *} \\
(0.016)\end{array}$ & $\begin{array}{c}-0.062^{* * *} \\
(0.016)\end{array}$ & $\begin{array}{c}-0.067 * * * \\
(0.016)\end{array}$ \\
\hline Parents Some College & $\begin{array}{l}-0.066 \\
(0.081)\end{array}$ & $\begin{array}{l}-0.066 \\
(0.082)\end{array}$ & $\begin{array}{l}-0.024 \\
(0.082)\end{array}$ \\
\hline Parents Bachelor Degree or More & $\begin{array}{l}-0.035 \\
(0.092)\end{array}$ & $\begin{array}{l}-0.052 \\
(0.093)\end{array}$ & $\begin{array}{l}-0.012 \\
(0.092)\end{array}$ \\
\hline Income in $[\$ 20000, \$ 40000]$ & $\begin{array}{c}-0.240^{* * *} \\
(0.083)\end{array}$ & $\begin{array}{c}-0.226 * * * \\
(0.083)\end{array}$ & $\begin{array}{c}0.067 \\
(0.124)\end{array}$ \\
\hline Income more than $\$ 40000$ & $\begin{array}{c}-0.288^{* * *} \\
(0.089)\end{array}$ & $\begin{array}{c}-0.259 * * * \\
(0.089)\end{array}$ & $\begin{array}{c}0.255^{* *} \\
(0.123)\end{array}$ \\
\hline Lagged ED-BN Index & $\begin{array}{c}0.149 * * * \\
(0.035)\end{array}$ & $\begin{array}{c}0.206^{* * *} \\
(0.036)\end{array}$ & $\begin{array}{c}0.318^{* * *} \\
(0.042)\end{array}$ \\
\hline \multicolumn{4}{|c|}{ Interaction with Lagged ED-BN Index: } \\
\hline White & & $\begin{array}{c}-0.146^{* * *} \\
(0.050)\end{array}$ & \\
\hline Income in $[\$ 20000, \$ 40000]$ & & & $\begin{array}{c}-0.145^{* *} \\
(0.058)\end{array}$ \\
\hline Income more than $\$ 40000$ & & & $\begin{array}{c}-0.362^{* * *} \\
(0.057)\end{array}$ \\
\hline Sample Size & 5426 & 5426 & 5426 \\
\hline
\end{tabular}

Notes: Results in all columns are with interpolated values of the indices and include all control variables as in Table 6 column (6). Robust clustered standard errors are in parenthesis. * significant at $10 \%$; ** at $5 \%$ and $* * *$ at $1 \%$. 
Table 8: Tobit Partial Effects Estimates for the Persistence of the ED-BN Index

\begin{tabular}{|c|c|c|c|c|c|}
\hline & $(1)$ & (2) & (3) & (4) & (5) \\
\hline Lagged ED-BN Index & $\begin{array}{l}0.270 * * * \\
(0.013)\end{array}$ & $\begin{array}{l}0.200 * * * \\
(0.012)\end{array}$ & $\begin{array}{c}0.184 * * * \\
(0.009)\end{array}$ & $\begin{array}{l}0.190 * * * \\
(0.013)\end{array}$ & $\begin{array}{l}0.180^{* * *} \\
(0.013)\end{array}$ \\
\hline White & & $\begin{array}{l}-0.077 \\
(0.070)\end{array}$ & $\begin{array}{c}-0.104 * * \\
(0.060)\end{array}$ & & \\
\hline Age & & $\begin{array}{c}-0.041 * * * \\
(0.013)\end{array}$ & $\begin{array}{c}-0.036 * * * \\
(0.067)\end{array}$ & & \\
\hline Parents Some College & & $\begin{array}{c}0.096 \\
(0.083)\end{array}$ & $\begin{array}{c}0.035 \\
(0.067)\end{array}$ & & \\
\hline $\begin{array}{l}\text { Parents Bachelor Degree } \\
\text { or More }\end{array}$ & & $\begin{array}{c}0.127 \\
(0.095)\end{array}$ & $\begin{array}{c}0.065 \\
(0.079)\end{array}$ & & \\
\hline Income in $[\$ 20000, \$ 40000]$ & & $\begin{array}{c}-0.224 * * * \\
(0.076)\end{array}$ & $\begin{array}{c}-0.160 * * * \\
(0.065)\end{array}$ & & \\
\hline Income more than $\$ 40,000$ & & $\begin{array}{c}-0.169 * * \\
(0.086)\end{array}$ & $\begin{array}{c}-0.160 * * * \\
(0.065)\end{array}$ & & \\
\hline Distrust Index & & $\begin{array}{l}-0.007 \\
(0.010)\end{array}$ & $\begin{array}{l}-0.001 \\
(0.009)\end{array}$ & $\begin{array}{l}-0.015 \\
(0.012)\end{array}$ & $\begin{array}{l}-0.015 \\
(0.012)\end{array}$ \\
\hline Ineffectiveness Index & & $\begin{array}{c}0.123^{* * *} \\
(0.010)\end{array}$ & $\begin{array}{l}0.118^{* * *} \\
(0.009)\end{array}$ & $\begin{array}{c}0.114 * * * \\
(0.011)\end{array}$ & $\begin{array}{c}0.099 * * * \\
(0.011)\end{array}$ \\
\hline Perfectionism Index & & $\begin{array}{l}0.066^{* * * *} \\
(0.009)\end{array}$ & $\begin{array}{l}0.060 * * * \\
(0.008)\end{array}$ & $\begin{array}{l}0.092 * * * \\
(0.013)\end{array}$ & $\begin{array}{c}0.044 * * * \\
(0.018)\end{array}$ \\
\hline Body Dissatisfaction Index & & & $\begin{array}{c}0.019 * * * \\
(0.003)\end{array}$ & & $\begin{array}{c}0.033^{* * *} \\
(0.007)\end{array}$ \\
\hline Interpolated Indices & No & No & No & No & No \\
\hline $\begin{array}{l}\text { Chamberlain/Wooldridge } \\
\text { Fixed Effects }\end{array}$ & No & No & No & Yes & Yes \\
\hline Sample Size & 4151 & 3938 & 3928 & 3938 & 3928 \\
\hline
\end{tabular}

Notes: Standard errors robust intra-individual correlation .

* indicates significant at $10 \%$; ** significant at $5 \%$; *** significant at $1 \%$. 
Table 9: Explaining State Dependence -- Two-Stage Least Squares Regression Estimates

\begin{tabular}{|c|c|c|c|c|}
\hline & (1) & (2) & (3) & (4) \\
\hline \multicolumn{5}{|l|}{ Number of Periods Lagged ED-BN Index } \\
\hline One Period & $\begin{array}{c}0.149 * * * \\
(0.035)\end{array}$ & $\begin{array}{l}0.120^{*} \\
(0.065)\end{array}$ & $\begin{array}{c}0.140 * * * \\
(0.042)\end{array}$ & $\begin{array}{c}0.136^{* * *} \\
(0.045)\end{array}$ \\
\hline Two Periods & & $\begin{array}{c}0.111 * * * \\
(0.037)\end{array}$ & & \\
\hline \multicolumn{5}{|l|}{ Bulimic Stock Variables } \\
\hline Intensity Stock (sum of ED-BN Index) & & & $\begin{array}{c}0.007 \\
(0.017)\end{array}$ & \\
\hline \multicolumn{2}{|c|}{ Threshold Stock (sum of binary if ED-BN Index $>6$ ) } & & & $\begin{array}{c}0.138 \\
(0.269)\end{array}$ \\
\hline
\end{tabular}

Notes: Results in all columns are with interpolated values of the indices and include all control variables as in Column (6) of Table 6. Robust clustered standard errors are in parenthesis. * significant at 10\%; $* *$ at $5 \%$ and $* * *$ at $1 \%$. 


\section{Appendix}

\section{A Data Variable Definitions}

We describe the construction of the ED-BN index in the main text of the paper. The body dissatisfaction index is based on the subjects responses to nine items: 1) I think that my stomach is too big, 2) I think that my thighs are too large, 3) I think that my stomach is just the right size, 4) I feel satisfied with the shape of my body, 5) I like the shape of my buttocks, 6) I think my hips are too big, 7) I think that my thighs are just the right size, 8) I think that my buttocks are too large, 9) I think my hips are just the right size. This index ranges from 0 to 27 , and responses are scored such that a higher score indicates more dissatisfaction. ${ }^{53}$

The perfectionism index is based on subject responses to six items: 1) In my family everyone has to do things like a superstar; 2) I try very hard to do what my parents and teachers want; 3) I hate being less than best at things; 4) My parents expect me to be the best; 5) I have to do things perfectly or not to do them at all; 6) I want to do very well. The subjects are offered the same responses, and the responses are scored in the same way as the ED-BN index.

The distrust index is based on the subjects responses to seven items: 1) I tell people about my feelings; 2) I trust people; 3) I can talk to other people easily; 4) I have close friends; 5) I have trouble telling other people how I feel; 6) I don't want people to get to know me very well; and 7) I can talk about my private thoughts or feelings. The scoring rule is as follows: "always" $=1$, "usually" $=2$, "often" $=3$, "sometimes" $=4$, "rarely" $=5$, and "never" $=6$ in questions 5 and 6 ; and "always" $=6$, "usually" $=5$, "often" $=4$, "sometimes" $=3$, "rarely" $=2$, and "never" $=1$ in questions $1,2,3,4$, and 7 . A response of 4- 6 on a given question contributes zero points to the distrust index; a response of 3 contributes 1 point; a response of 2 contributes 2 points; and a response of 1 contributes 3 points. The distrust index is a sum of all contributing points.

The ineffectiveness index is based on the subjects responses to ten items: 1) I feel I can't do things very well; 2) I feel very alone; 3) I feel I can’t handle things in my life; 4) I wish I were someone else; 5) I don't think I am as good as other kids; 6) I feel good about myself; 7) I don't like myself very much; 8) I feel I can do whatever I try to do; 9) I feel I am a good person; 10) I feel empty inside. The scoring rule is as follows: "always" $=1$, "usually" $=2$, "often" $=3$,

\footnotetext{
53 The scoring rule is as follows: "always" $=6$, "usually" $=5$, "often" $=4$, "sometimes" $=3$, "rarely" $=2$, and "never" $=1$ in questions $3,4,5,7$, and 9 and "always" $=1$, "usually" =2, "often" =3, "sometimes" =4, "rarely" =5, and "never" =6 in questions 1, 2, 6, and 8. Again a response of 4-6 on a given question contributes zero points to the body image index; a response of 3 contributes 1 point; a response of 2 contributes 2 points; and a response of 1 contributes 3 points. The body image index is the sum of the contributing points.
} 
"sometimes" $=4$, "rarely" $=5$, and "never" $=6$ in questions $1,2,3,4,5,7$, and 10; and "always" $=6$, "usually" =5, "often" =4, "sometimes" $=3$, "rarely" $=2$, and "never" $=1$ in questions 6,8 , and 9 .

A response of 4-6 on a given question contributes zero points to the ineffectiveness index; a response of 3 contributes 1 point; a response of 2 contributes 2 points; and a response of 1 contributes 3 points. The ineffectiveness index is a sum of all contributing points.

Table A1 provides more details on the variables used in the paper.

Table A.1: Variable Definitions

\begin{tabular}{|c|c|c|c|}
\hline Variable & Description & Coding & Waves \\
\hline ED-BN Index & Eating Disorders Bulimia Subscale & Categorical Variable; Range 0-21 & $3,5,7,9,10$ \\
\hline Clinical Bulimia & Case of Clinical Bulimia & $=1$ if ED-BN Index $>10 ;=0$ Otherwise & $3,5,7,9,10$ \\
\hline Body Dissatisfaction Index & Measures Poor Body Image Concerns & Categorical Variable; Range 0-27 & $3,5,7,9,10$ \\
\hline Perfectionism Index & Measures Driveness for Perfection & Categorical Variable; Range $0-18$ & $3,5,9,10$ \\
\hline Ineffectiveness Index & Measures Feelings of Ineffectiveness & Categorical Variable; Range 0-29 & $3,5,9,10$ \\
\hline Distrust Index & Measures Interpersonal Distrust & Categorical Variable; Range $0-21$ & $3,5,9,10$ \\
\hline Age & Respondent Age & & All 10 \\
\hline White & Respondent Race is White & $=1$ if Race is White; $=0$ if African American & 1 \\
\hline Parents High School or Less & Highest Education of Parents & Dummy Variable Highest Education High School or Less & 1 \\
\hline Parents Some College & Highest Education of Parents & Dummy Variable Highest Education Some College & 1 \\
\hline Parents Bachelor Degree or More & Highest Education of Parents & Dummy Variable Highest Education College Degree or More & 1 \\
\hline Income less than $\$ 20,000$ & Household income (in 1988\$) & Dummy Variable Household Income is Less than $\$ 20,000$ & 1 \\
\hline Income in $[\$ 20000, \$ 40000]$ & Household income (in 1988\$) & Dummy Variable Household Income is in Range $[\$ 20,000, \$ 40,000]$ & 1 \\
\hline Income more than $\$ 40,000$ & Household income (in 1988\$) & Dummy Variable Household Income is Higher than $\$ 40,000$ & 1 \\
\hline
\end{tabular}

